\title{
2-Hydroxysorangiadenosine: Structure and Biosynthesis of a Myxobacterial Sesquiterpene-Nucleoside
}

\author{
Dorothy A. Okoth ${ }^{1,2,+}$, Joachim J. Hug $1,2,+\oplus$, Ronald Garcia ${ }^{1,2}$, Cathrin Spröer ${ }^{3}$, \\ Jörg Overmann 2,3 and Rolf Müller 1,2,*(D) \\ 1 Department Microbial Natural Products, Helmholtz-Institute for Pharmaceutical Research Saarland (HIPS), \\ Helmholtz Centre for Infection Research (HZI) and Department of Pharmacy, Saarland University, \\ Campus E8 1, 66123 Saarbrücken, Germany; Dorothy.Okoth@helmholtz-hips.de (D.A.O.); \\ Joachim.Hug@helmholtz-hips.de (J.J.H.); Ronald.Garcia@helmholtz-hips.de (R.G.) \\ 2 German Center for Infection Research (DZIF), Partner Site Hannover-Braunschweig, 38124 Braunschweig, \\ Germany; joerg.overmann@dsmz.de \\ 3 Leibniz Institute DSMZ-German Collection of Microorganisms and Cell Cultures, 38124 Braunschweig, \\ Germany; Cathrin.Sproeer@dsmz.de \\ * Correspondence: rolf.mueller@helmholtz-hips.de \\ + These authors contributed equally.
}

Received: 20 May 2020; Accepted: 5 June 2020; Published: 9 June 2020

\begin{abstract}
Myxobacteria represent an under-investigated source for biologically active natural products featuring intriguing structural moieties with potential applications, e.g., in the pharmaceutical industry. Sorangiadenosine and the here-discovered 2-hydroxysorangiadenosine are myxobacterial sesquiterpene-nucleosides with an unusual structural moiety, a bicyclic eudesmane-type sesquiterpene. As the biosynthesis of these rare terpene-nucleoside hybrid natural products remains elusive, we investigated secondary metabolomes and genomes of several 2-hydroxysorangiadenosine-producing myxobacteria. We report the isolation and full structure elucidation of 2-hydroxysorangiadenosine and its cytotoxic and antibiotic activities and propose a biosynthetic pathway in the myxobacterium Vitiosangium cumulatum MCy10943 ${ }^{\mathrm{T}}$.
\end{abstract}

Keywords: myxobacteria; terpene-nucleoside; biosynthesis; antibiotics; sorangiadenosine; 2-hydroxysorangiadenosine; secondary metabolites; genome-mining; antibiotics; natural products discovery

\section{Introduction}

Myxobacteria are remarkable Gram-negative bacteria exhibiting several unusual characteristics, such as coordinated movement by gliding and creeping on surfaces in a swarm-like pattern [1]. Unlike other prokaryotes, they show unique cooperative "social behavior", based on complex chemical communication systems [2]. A wide variety of modes of action have been documented for myxobacterial secondary metabolites with diverse bioactivities [3], such as the antifungal soraphen A [4], the antibacterial cystobactamid 919-2 [5], the antiplasmodial chlorotonil [6], the antiviral aetheramides [7] and the cytotoxic pretubulysin [8,9]. Most of these compounds derive biosynthetically from giant biosynthetic enzyme complexes such as modular polyketide synthases (PKSs), non-ribosomal peptide synthetases (NRPSs) and hybrids thereof, while natural products from other biosynthetic machineries have been less frequently isolated.

Terpene natural products in myxobacteria have primarily been investigated by analysis of the volatiles emitted from cell cultures of Myxococcus xanthus sp. [10] and Stigmatella aurantiaca sp. [11] 
through a closed-loop stripping apparatus and subsequent gas chromatography-mass spectrometry (GC-MS) analysis. These investigations revealed not only the biosynthesis of several myxobacterial volatiles through stable isotope-labeled precursor feeding but also permitted further insights into the formation of the well-known terpenes geosmin [12] and 2-methylisoborneol [13,14]. The biosynthetic characterization of (+)-eremophilene biosynthesis [15] and the function of terpene synthase Soce6369 (10-epi-cubenol synthase) [16] in Sorangium cellulosum Soce56 provided additional in-depth knowledge of terpene biosynthesis in myxobacteria.

The sesquiterpene adenoside sorangiadenosine (1) has been isolated from the crude organic extract of Sorangium cellulosum KM1003 [17]. Evaluation of its biological function indicated moderate antibacterial activity against the test strains Staphylococcus aureus ATCC 6538p, Bacillus subtilis ATCC 6633, Micrococcus luteus IFC 12708, Proteus vulgaris ATCC 3851, Salmonella typhimurium ATCC 14028, and Escherichia coli ATCC 25922 [17]. Our current interest was focused on deciphering the biosynthetic logic of this terpene-nucleoside hybrid. Terpene-nucleoside hybrids are a rarely described class of natural products, reflected by the fact that $\mathbf{1}$ is the only known terpene-nucleoside hybrid from a myxobacterium.

We report here the isolation and the cytotoxic and antibacterial activities together with the full structure elucidation of the new sorangiadenosine derivative 2-hydroxysorangiadenosine (2) from the myxobacterial producer Vitiosangium cumulatum MCy10943 ${ }^{\mathrm{T}}$ [18], which belongs to a different myxobacterial family than the previously described producer of $\mathbf{1}$. In addition, genome sequencing of the producer strain V. cumulatum MCy $10943^{\mathrm{T}}$ and comparative metabolome analysis of several additional myxobacterial strains led to the identification of a putative biosynthetic gene cluster (BGC) involved in the formation of $\mathbf{1}$ and $\mathbf{2}$ (Figure 1).

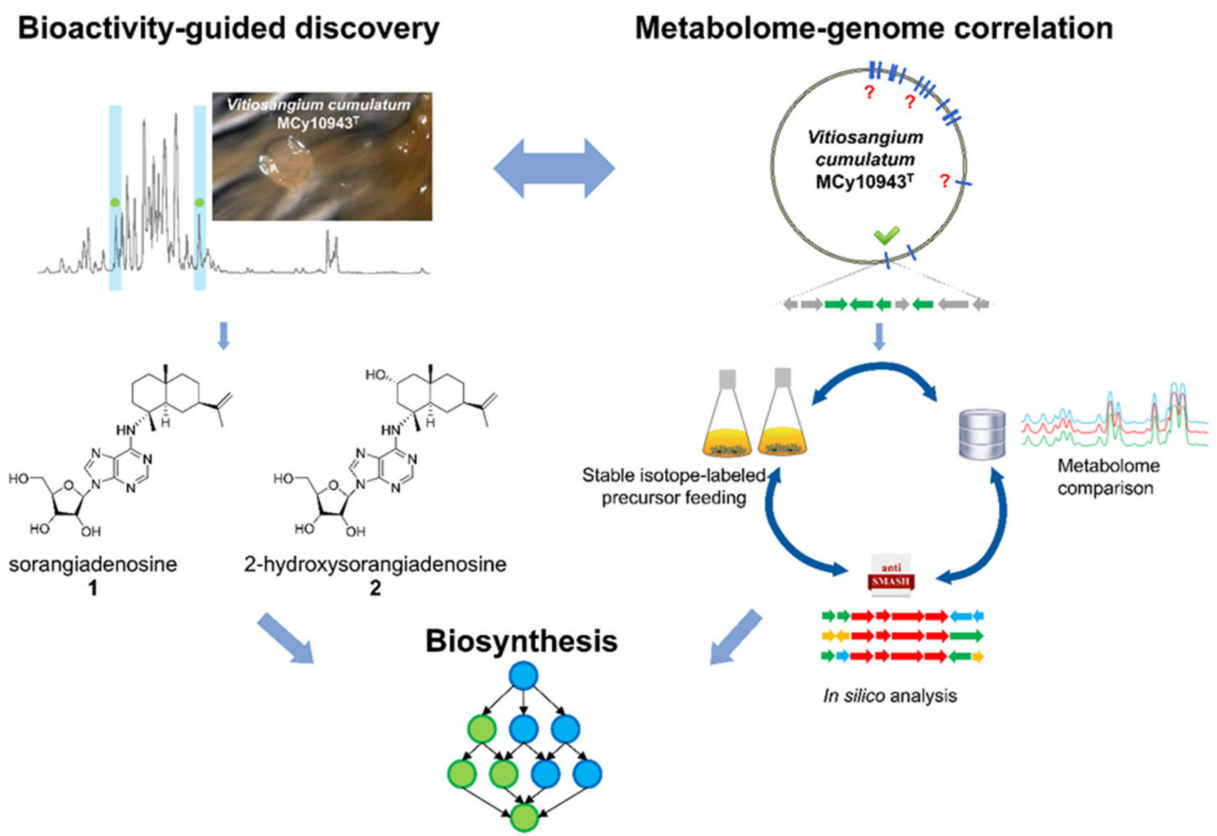

Figure 1. Bioactivity-guided metabolome screening of Vitiosangium cumulatum MCy $10943^{\mathrm{T}}$ led to the re-discovery of sorangiadenosine (1) and the discovery of 2-hydroxysorangiadenosine (2). The molecular weight, sum formula and $\mathrm{MS}^{2}$ fragmentation pattern of the unknown molecules enabled identification and isolation of $\mathbf{1}$ and $\mathbf{2}$. The corresponding biosynthetic gene cluster was identified via in-silico investigation of the MCy $10943^{\mathrm{T}}$ genome sequence. Stable isotope-labeled precursor feeding experiments and comparative metabolome investigation of genome-sequenced myxobacterial strains corroborated this analysis. Finally, the outcome of this study led to a proposed biosynthetic route responsible for the biosynthesis of these unique sesquiterpene-adenosine hybrids. 


\section{Results}

\subsection{Discovery of 2-Hydroxysorangiadenosine and Sorangiadenosine}

In the course of our bioactivity-guided secondary metabolite screening of the recently isolated strain V. cumulatum MCy10943 ${ }^{\mathrm{T}}$ [18] (Figure 2A), high-performance liquid chromatography (HPLC)-fractions of the crude extract active against Bacillus subtilis revealed two target masses. One secondary metabolite features an ion peak in the liquid chromatography-mass spectrometry (LC-MS) chromatogram at mass-to-charge ratio $(\mathrm{m} / \mathrm{z}) 472.2924[\mathrm{M}+\mathrm{H}]^{+}$, supporting the deduced molecular formula $\mathrm{C}_{25} \mathrm{H}_{38} \mathrm{~N}_{5} \mathrm{O}_{4}$ at the retention time of $11.72 \mathrm{~min}$, while the second target mass features an ion peak at $\mathrm{m} / \mathrm{z} 488.2873$ $[\mathrm{M}+\mathrm{H}]^{+}$, supporting the deduced molecular formula $\mathrm{C}_{25} \mathrm{H}_{38} \mathrm{~N}_{5} \mathrm{O}_{5}$ at the retention time of $8.24 \mathrm{~min}$ (Figure 2B). A search in several chemical structure databases revealed that the target mass of 472.2924 $[\mathrm{M}+\mathrm{H}]^{+}$might correspond to the previously isolated natural product 1 , whereas the second natural product 2 could be a derivative thereof, according to the observed tandem mass spectrometry $\left(\mathrm{MS}^{2}\right)$ fragmentation pattern of both compounds. The $\mathrm{MS}^{2}$ fragment of $\mathbf{1}$ was characterized by $m / z 340.2509\left(\mathrm{C}_{20} \mathrm{H}_{30} \mathrm{~N}_{5}{ }^{+}\right), 268.1047\left(\mathrm{C}_{10} \mathrm{H}_{14} \mathrm{~N}_{5} \mathrm{O}_{4}{ }^{+}\right)$and $205.1959\left(\mathrm{C}_{15} \mathrm{H}_{25}{ }^{+}\right)$, consistent with

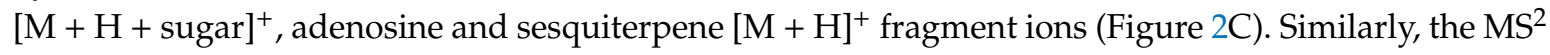
fragment of compound 2 was characterized by $m / z 356.2453[\mathrm{M}+\mathrm{H}]^{+}\left(\mathrm{C}_{20} \mathrm{H}_{30} \mathrm{~N}_{5} \mathrm{O}^{+}\right), m / z 268.1043$ $\left(\mathrm{C}_{10} \mathrm{H}_{14} \mathrm{~N}_{5} \mathrm{O}_{4}{ }^{+}\right)$and $m / z 203.1799\left(\mathrm{C}_{15} \mathrm{H}_{23}{ }^{+}\right)$consistent with $[\mathrm{M}+\mathrm{H}+\text { sugar }]^{+}$, [adenosine $\left.+\mathrm{H}\right]^{+}$, and $[\mathrm{M}+\mathrm{H}+\text { adenosine }+\mathrm{OH}]^{+}$ion peaks (Figure 2D). This suggested that both compounds were made of a sesquiterpene, adenine and a sugar moiety, with compound $\mathbf{2}$ having an additional oxygen atom (Figure 2C,D). Since S. cellulosum KM1003, the original myxobacterial producer of 1, was not deposited in a publicly accessible collection, and a reference substance was not commercially available, the identity of the detected compound was validated via isolation and structure elucidation of the identified compounds. The recorded proton $\left({ }^{1} \mathrm{H}\right)$ nuclear magnetic resonance (NMR) and carbon-13 $\left({ }^{13} \mathrm{C}\right) \mathrm{NMR}$ of both purified compounds proved the identity of these compounds as $\mathbf{1}$ and the new derivative 2 (Figure 3).

The ${ }^{1} \mathrm{H}$ NMR and ${ }^{13} \mathrm{C}$ NMR data of 1 was consistent with the observed correlations of the previously isolated sorangiadenosine from a S. cellulosum KM1003 [17]. The ${ }^{1} \mathrm{H}$ and ${ }^{13} \mathrm{C}-\mathrm{NMR}$ data of 2 resembled that of $\mathbf{1}$. The heteronuclear single quantum coherence/correlation (HSQC) and ${ }^{13} \mathrm{C}-\mathrm{NMR}$ of 1 showed 25 carbons; six quaternary, eight methines, eight methylenes and three methyl groups; the HSQC and ${ }^{13} \mathrm{C}-\mathrm{NMR}$ for 2 showed 25 carbons; six quaternary, nine methines, seven methylenes and three methyl groups. Like 1, a combination of one-dimensional (1D) and 2D NMR indicated that 2 also consists of a heteroaromatic moiety (adenine), a pentose sugar and a sesquiterpene.

The structure of the sesquiterpene was fully elucidated based on its ${ }^{1} \mathrm{H}$ and ${ }^{13} \mathrm{C}-\mathrm{NMR}$ data. Fifteen carbons (three quaternary carbons, three methyl groups, six methylenes, two methines, one oxymethine) were assigned to the sesquiterpene moiety. The NMR spectra of 2 were similar to 1 [17], with the exception of a secondary alcohol $\left(\delta_{\mathrm{C}} 65.6, \delta_{\mathrm{H}} 3.94,1 \mathrm{H}, \mathrm{m}\right) .{ }^{1} \mathrm{H}-{ }^{1} \mathrm{H}$ correlation spectroscopy (COSY) correlations were observed between the oxymethine proton $\left(\delta_{\mathrm{H}} 3.94, \mathrm{~m}\right)$ and two pairs of methylene protons $\mathrm{H}-1\left(\delta_{\mathrm{H}} 1.27,1 \mathrm{H}, \mathrm{t}\right.$ and $\left.1.80,1 \mathrm{H}, \mathrm{dd}\right)$ and $\mathrm{H}-3\left(\delta_{\mathrm{H}} 2.52,1 \mathrm{H}, \mathrm{t}\right.$ and $\left.2.41,1 \mathrm{H}, \mathrm{m}\right)$ indicated a partial structure of $-\mathrm{CH}_{2}-\mathrm{CH}(\mathrm{OH})-\mathrm{CH}_{2}-$. Further COSY correlations of $\mathrm{H}-6\left(\delta_{\mathrm{H}} 1.70\right.$, $1 \mathrm{H}, \mathrm{m}$ and $\left.\delta_{\mathrm{H}} 1.38,1 \mathrm{H}, \mathrm{t}\right)$ to $\mathrm{H}-5\left(\delta_{\mathrm{H}} 2.60,1 \mathrm{H}, \mathrm{dd}\right)$ and $\mathrm{H}-7\left(\delta_{\mathrm{H}} 1.94,1 \mathrm{H}, \mathrm{m}\right), \mathrm{H}-8\left(\delta_{\mathrm{H}} 1.56,1 \mathrm{H}, \mathrm{m}\right.$ and $\left.\delta_{\mathrm{H}} 1.38,1 \mathrm{H}, \mathrm{t}\right)$ to $\mathrm{H}-7\left(\delta_{\mathrm{C}} 1.94,1 \mathrm{H}, \mathrm{m}\right)$ and $\mathrm{H}-9\left(\delta_{\mathrm{H}} 1.52,1 \mathrm{H}, \mathrm{m}\right.$ and $\left.\delta_{\mathrm{H}} 1.38,1 \mathrm{H}, \mathrm{t}\right)$ lead to formation of another partial structure of $-\mathrm{CH}-\mathrm{CH}_{2}-\mathrm{CH}-\mathrm{CH}_{2}-\mathrm{CH}_{2}-{ }^{1} \mathrm{H}_{-}{ }^{13} \mathrm{C}$ heteronuclear multiple bond correlation (spectroscopy) (HMBC) correlations between $\mathrm{H}-3$ protons $\left(\delta_{\mathrm{H}} 2.521 \mathrm{H}, \mathrm{t}\right.$ and $2.41,1 \mathrm{H}$, $\mathrm{m})$ and $\mathrm{C}-15\left(\delta_{\mathrm{C}} 22.4\right), \mathrm{C}-1\left(\delta_{\mathrm{C}} 50.8\right), \mathrm{C}-2\left(\delta_{\mathrm{C}} 65.6\right)$ and C-4 $\left(\delta_{\mathrm{C}} 60.4\right)$ were observed. Further ${ }^{1} \mathrm{H}_{-}{ }^{13} \mathrm{C}$ HMBC correlations were observed between (H-1 protons) $\delta_{\mathrm{H}} 1.27$ and 1.80 and C-14 $\left(\delta_{\mathrm{C}} 20.7\right), \mathrm{C}-3$ $\left(\delta_{C} 46.6\right), C-10\left(\delta_{C} 35.6\right), C-2\left(\delta_{C} 65.6\right)$ and C-9 $\left(\delta_{C} 46.4\right)$. These enabled the assignment of the alcohol at C-2. Additional HMBC cross peaks between $\mathrm{H}-5$ proton $\left(\delta_{\mathrm{H}} 2.60\right)$ and $\mathrm{C}-1\left(\delta_{\mathrm{C}} 50.8\right), \mathrm{C}-4\left(\delta_{\mathrm{C}} 60.4\right)$, $C-10\left(\delta_{C} 35.6\right), C-14\left(\delta_{C} 20.7\right)$ and between H-14 methyl protons to C-10 $\left(\delta_{C} 35.6\right), C-9\left(\delta_{C} 46.4\right)$ and C-5 $\left(\delta_{\mathrm{C}} 48.5\right)$ allowed the completion of the bicyclic ring. The vinyl signals $\left(\delta_{\mathrm{C}} 109.0(\mathrm{C}-13), \delta_{\mathrm{H}} 4.65(\mathrm{H}-13)\right.$ 
and $\left.\delta_{C} 151.5(\mathrm{C}-11)\right)$ and a methyl group $\left(\delta_{\mathrm{C}} 21.1, \delta_{\mathrm{H}} 1.68\right)$ corresponded to the sesquiterpene head in eudesmane-type sesquiterpenes. HMBC correlations between the $\mathrm{H}-7$ proton $\left(\delta_{\mathrm{H}} 1.94,1 \mathrm{H}, \mathrm{m}\right)$ and $\mathrm{C}-13\left(\delta_{C} 109.0\right), \mathrm{C}-11\left(\delta_{C} 151.5\right)$ and $\mathrm{C}-12\left(\delta_{C} 21.1\right)$ confirmed the attachment of the isopropylene unit at $\mathrm{C}-7$ of the sesquiterpene ring.

A

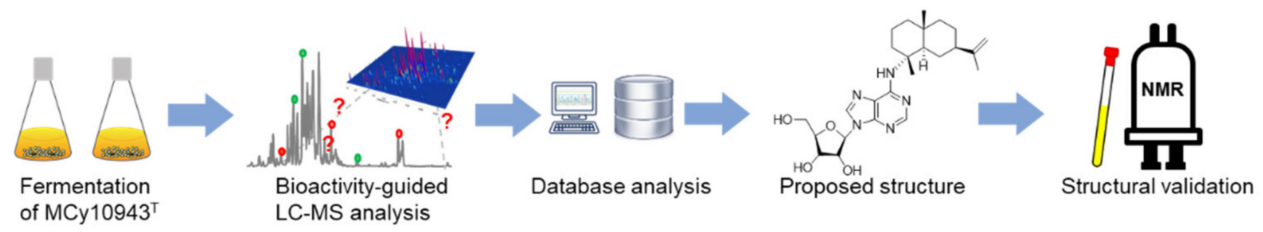

B

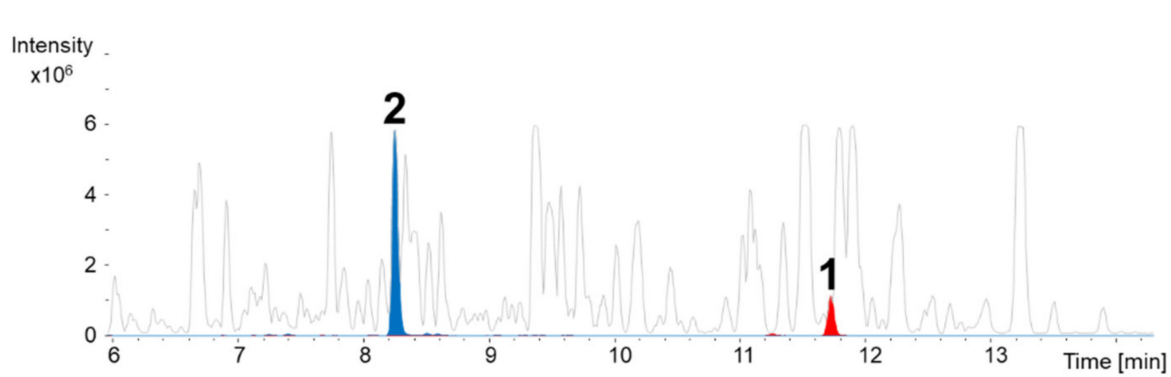

C
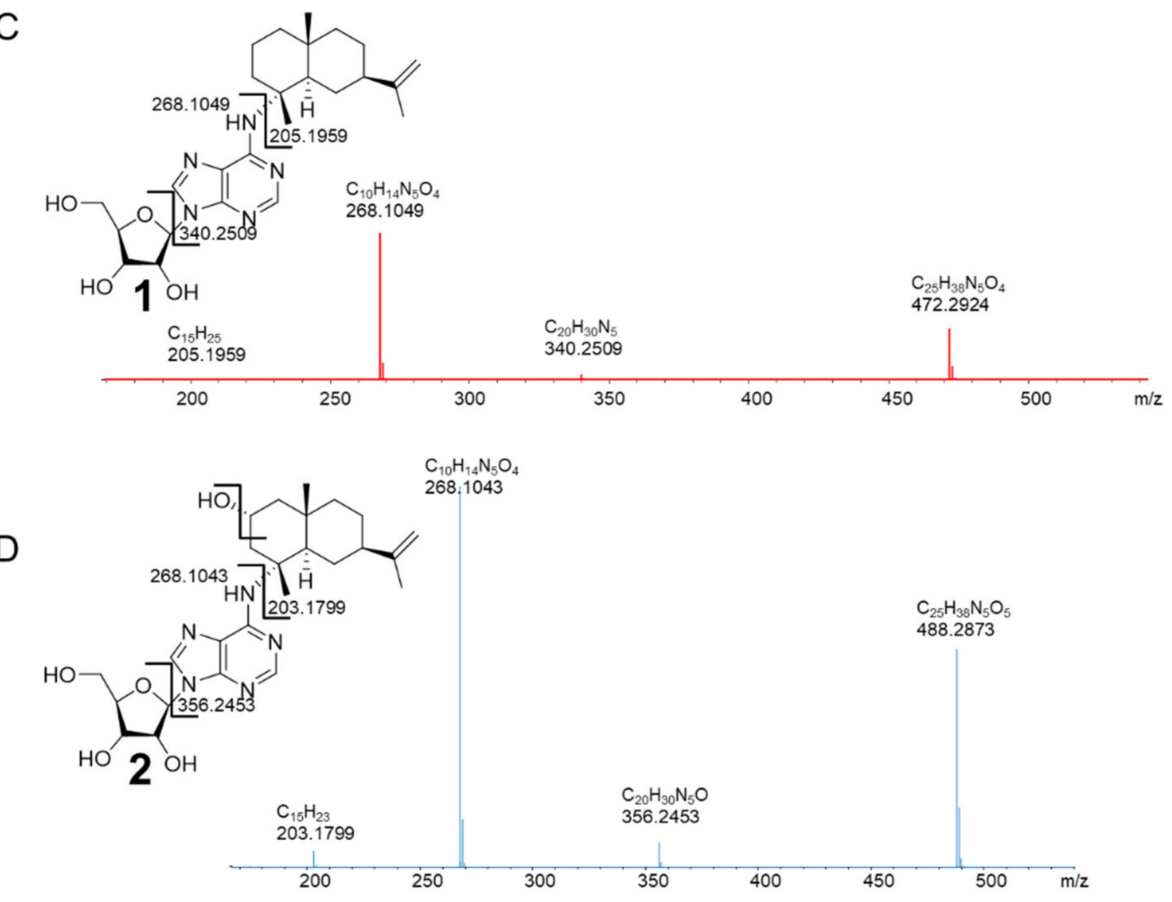

Figure 2. (A) Workflow of secondary metabolite screening in $\mathrm{MCy} 10943^{\mathrm{T}}$, resulting in the independent re-isolation of sorangiadenosine (1) and the discovery of 2-hydroxysorangiadenosine (2). (B) High-performance liquid chromatography-mass spectrometry base peak chromatogram (HPLC-MS BPC) (grey) and extracted ion chromatogram (EIC) of $\mathbf{1}\left([\mathrm{M}+\mathrm{H}]^{+} 472.2923 \mathrm{~m} / \mathrm{z}\right.$, red) and 2 $\left([\mathrm{M}+\mathrm{H}]^{+} 488.2873 \mathrm{~m} / \mathrm{z}\right.$, blue) from MCy $10943^{\mathrm{T}}$ crude extracts. Fragmentation of sorangiadenosine (C) and 2-hydroxysorangiadenosine (D) in $\mathrm{MS}^{2}$ experiments.

The relative stereochemistry at the asymmetric carbon centers at C-4, C-5, C-7, and C-10 was assigned by rotating frame nuclear Overhauser enhancement spectroscopy (ROESY) experiments.

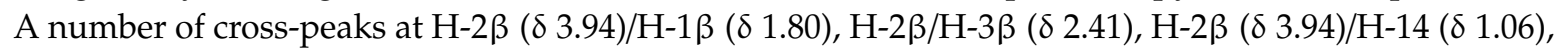

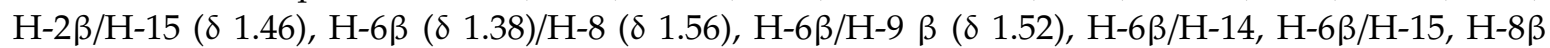
$(\delta 1.56) / \mathrm{H}-14$ and $\mathrm{H}-14 / \mathrm{H}-15$ were observed. These 1,3-diaxial correlations of $\mathrm{H}-14$ and $\mathrm{H}-15$ methyl 
protons and neighboring protons indicated that their orientation was axial. In contrast, other series of ROESY correlations at H-1 $\alpha(\delta$ 1.30)/H-3 $\alpha$ ( $\delta$ 2.52), H-1/H-5 ( $\delta 2.60), \mathrm{H}-1 / \mathrm{H}-9 \alpha(\delta$ 1.38), H-3/H-5, $\mathrm{H}-5 / \mathrm{H}-6 \alpha(\delta 1.70), \mathrm{H}-5 / \mathrm{H}-7$ ( $\delta 1.94), \mathrm{H}-5 / \mathrm{H}-12$ ( $\delta 1.68)$ and $\mathrm{H}-5 / \mathrm{H}-9 \alpha(\delta 1.38)$ showed that these protons had an opposite orientation at the decalin plane. Thus, the relative configurations were assigned to be trans (C-5 and C-10) and $2 R, 4 R, 5 R, 7 R, 10 S$ for the ring junction asymmetric carbons, respectively.

Assignment of the relative stereochemical configuration of the C-2 hydroxyl group was based on ROESY correlations observed between the $\mathrm{H}-2 \beta$ proton $\left(\delta_{\mathrm{H}} 3.94\right)$ and $\mathrm{C}-14\left(\delta_{\mathrm{H}} 1.06\right)$ and $\mathrm{C}-15$ $\left(\delta_{\mathrm{H}} 1.46\right)$ methyl groups. The presence of two downfield aromatic protons at $\delta_{\mathrm{H}} 8.24\left(1 \mathrm{H}, \mathrm{s}, \mathrm{H}-2^{\prime}\right)$ and $\delta_{\mathrm{H}} 8.26\left(1 \mathrm{H}, \mathrm{s}, \mathrm{H}-8^{\prime}\right)$ suggested they were connected to nitrogen atoms. These two protons were HMBC-coupled to five downfield carbons $\delta_{\mathrm{C}} 152.9\left(\mathrm{C}-2^{\prime}\right), 148.8\left(\mathrm{C}-4^{\prime}\right), 121.6\left(\mathrm{C}-5^{\prime}\right), 155.7\left(\mathrm{C}-6^{\prime}\right)$ and $141.2\left(\mathrm{C}-8^{\prime}\right)$ confirmed the presence of the adenine base [19]. Long-range HMBC correlations between the $C-15$ methyl proton signals $\left(\delta_{H} 1.46\right)$ attached to $C-4\left(\delta_{C} 60.4\right)$ of sesquiterpene and $C-6^{\prime}\left(\delta_{C} 155.7\right)$ of the adenine confirmed the position of linkage between the C-4 of eudesme-11-ne and the adenine base. The absence of any observable HMBC correlation between the C-15 methyl protons and the C- $2^{\prime}$ carbon of the adenine confirms that the point of sesquiterpene attachment cannot be at the $\mathrm{N}-1^{\prime}$ position of adenine.

The ribofuranosyl was characterized by six proton signals in the region 3.74-5. 94 in the ${ }^{1} \mathrm{H}-\mathrm{NMR}$ spectrum. Based on COSY, HSQC and HMBC correlations, five carbons $\delta_{\mathrm{C}} 91.3\left(\mathrm{C}-1^{\prime \prime}\right), 88.3\left(\mathrm{C}-4^{\prime \prime}\right), 75.4$ $\left(\mathrm{C}-2^{\prime \prime}\right), 72.7\left(\mathrm{C}-3^{\prime \prime}\right)$, and $63.5\left(\mathrm{C}-5^{\prime \prime}\right)$ were assigned to the sugar moiety. A coupling constant of $6.5 \mathrm{~Hz}$ of the anomeric proton $\mathrm{H}-1^{\prime \prime}\left(\delta_{\mathrm{H}} 5.94\right)$ and a larger magnitude $(>2.15 \mathrm{ppm})$ in the difference between $\mathrm{H}-2^{\prime}\left(\delta_{\mathrm{H}} 8.24\right)$ and $\mathrm{H}-1^{\prime \prime}\left(\delta_{\mathrm{H}} 5.94\right)$ protons indicated a $\beta$-anomer sugar [20]. The linkage between the adenine and ribose moiety was based on HMBC correlation between anomeric proton $\mathrm{H}_{-1} 1^{\prime \prime}\left(\delta_{\mathrm{H}} 5.94\right)$ and $\delta_{\mathrm{C}} 148.8\left(\mathrm{C}-4^{\prime}\right)$ and $141.2\left(\mathrm{C}-8^{\prime}\right)$. ROESY correlations observed between the anomeric proton $\mathrm{H}-1^{\prime \prime} / \mathrm{H}-4^{\prime \prime}, \mathrm{H}-1^{\prime \prime} / \mathrm{H}-2^{\prime \prime}, \mathrm{H}-1^{\prime \prime} / \mathrm{H}-3^{\prime \prime}$ and between $\mathrm{H}-2^{\prime \prime} / \mathrm{H}-3^{\prime \prime}$ and $\mathrm{H}-2^{\prime} / \mathrm{H}-4^{\prime}$ suggest a cis conformation of the H-2" and $\mathrm{H}-3^{\prime \prime}$ hydroxyl groups. Comparison of the NMR data with the literature values suggested a D-ribose sugar [21]. In addition, the observed optical rotations of both compounds $\left(\mathbf{1}[\alpha]^{20} \mathrm{D}-76.92(\mathrm{MeOH})\right.$ and $\mathbf{2}[\alpha]^{20} \mathrm{D}-70.92(\mathrm{MeOH})$ were negative as in the case of previously isolated $\mathbf{1}[\alpha]^{20}{ }_{D}-78.7$ [17]. Moreover, the circular dichroism (CD) spectrum of 2 shows two negative cotton effect bands at 260 and $215 \mathrm{~nm}$ (Figure S13), consistent with the CD spectrum from adenosine [22-24], which features, like most of the naturally-occurring monosaccharides, a D-configured ribose [22-24]. Finally, the subsequently identified biosynthetic origin of $\mathbf{1}$ and $\mathbf{2}$ strikingly suggests a D-configured ribose (see below).
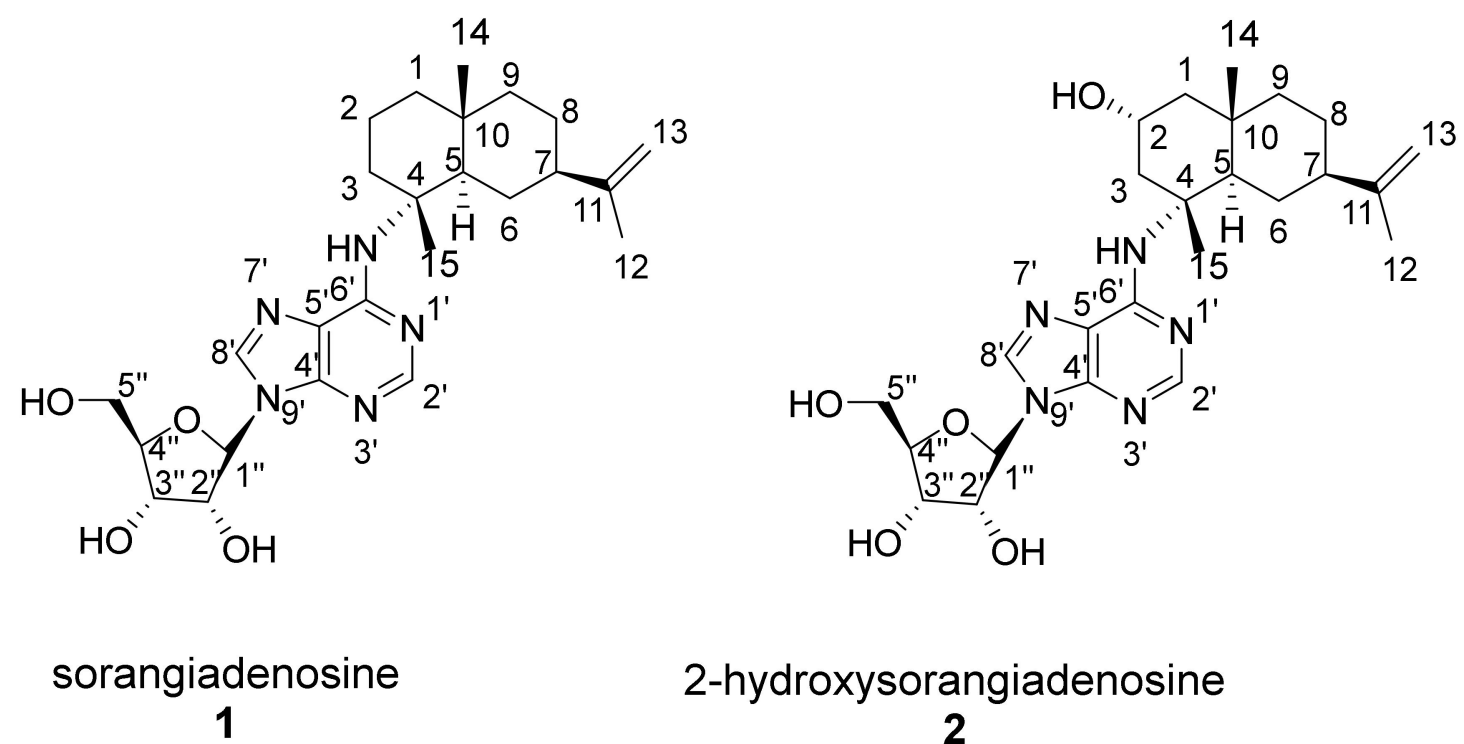

\section{2-hydroxysorangiadenosine}

2

Figure 3. Chemical structure and numbering of sorangiadenosine (1) and 2-hydroxysorangiadenosine (2). 


\subsection{Biological Activity of 2-Hydroxysorangiadenosine and Sorangiadenosine}

The sesquiterpene-nucleoside compounds $\mathbf{1}$ and $\mathbf{2}$ showed biological activity against the Gram-positive bacteria Bacillus subtilis DSM10 and Staphylococcus aureus Newman (Table 1). 1 was cytotoxic towards HCT (human colon carcinoma cell line, DSMZ No. ACC 581) and KB3.1 cells at IC 50 of $30.0 \mu \mathrm{g} / \mathrm{mL}$ and $39.46 \mu \mathrm{g} / \mathrm{mL}$ while 2 featured activity against HCT cell lines at $\mathrm{IC}_{50} \mathrm{of} 52.0 \mu \mathrm{g} / \mathrm{mL}$ (Table 2). In conclusion, $\mathbf{1}$ shows better bioactivity compared to $\mathbf{2}$. This may be due to the additional oxygen atom in 2 , which significantly increases the polarity of the sesquiterpene-nucleoside scaffold and limits the cell membrane penetration capability of $\mathbf{2}$ (a finding also reflected in the difference of the retention times).

The results of our bioactivity profiling of $\mathbf{1}$ (and 2) resemble the findings of the previously observed antimicrobial range of $\mathbf{1}$ [17]. Despite the fact that former bioactivity screening of $\mathbf{1}$ displayed moderate bioactivity against the Gram-negative bacterium Proteus vulgaris ATCC 3851 (Minimum inhibitory concentration (MIC) at $6.25 \mu \mathrm{g} / \mathrm{mL}$ ) and Salmonella typhimurium ATCC 14028 (MIC at $12.5 \mu \mathrm{g} / \mathrm{mL}$ ) [17], the biological activity of these sesquiterpene-nucleosides seem to be focused on Gram-positive bacteria according to our findings. The lack of biological activity of $\mathbf{1}$ and $\mathbf{2}$ against E. coli test strains (E. coli wild type (WT) (DSM 1116) and E. coli acrB JW0451-2 see Table 1, Escherichia coli ATCC 25922 see Ahn et al. [17]) underlines this conclusion and highlights the difficulty of finding new compounds capable of, presumably, penetrating the outer membrane of Gram-negative bacteria [25,26].

Table 1. Minimum inhibitory concentration (MIC) values of sorangiadenosine and 2-hydroxysorangiadenosine (1 and $\mathbf{2}$ ) against common microbial pathogens.

\begin{tabular}{ccc}
\hline Microorganism & $\begin{array}{c}\text { MIC }(\mu \mathrm{g} / \mathbf{m L}) \text { of } \\
\text { Sorangiadenosine (1) }\end{array}$ & $\begin{array}{c}\text { MIC }(\mu \mathrm{g} / \mathbf{m L}) \text { of } \\
\text { 2-hydroxysorangiadenosine (2) }\end{array}$ \\
\hline B. subtilis DSM 10 & 16 & 64 \\
E. coli WT (DSM 1116) & $>128$ & $>128$ \\
E. coli acrB JW0451-2 & $>128$ & $>128$ \\
P. aeruginosa PA14 & $>128$ & $>128$ \\
S. aureus Newman & 32 & 128 \\
C. freundii DSM 30039 & $>128$ & $>128$ \\
A. baumanii DSM 30007 & $>128$ & $>128$ \\
M. hiemalis DSM 2656 & 128 & $>128$ \\
P. anomala DSM 6766 & $>128$ & $>128$ \\
M. smegmatis MC ${ }^{2}$ 155 & $>128$ & $>128$ \\
C. albicans DSM 1665 & 128 & $>128$ \\
\hline
\end{tabular}

Table 2. Half-maximal inhibitory concentrations ( $\mathrm{IC}_{50}$ values in $\mu \mathrm{g} / \mathrm{mL}$ ) of sorangiadenosine, 2-hydroxysorangiadenosine ( $\mathbf{1}$ and $\mathbf{2}$ ) and doxorubicin (used as cytotoxic positive control) against HCT-116 (human colon carcinoma cell line, DSMZ No. ACC 581) and KB-3-1 (cervix carcinoma cell line, DSMZ No. ACC 158).

\begin{tabular}{cccc}
\hline Cancer Cell Line & $\begin{array}{c}\mathrm{IC}_{\mathbf{5 0}}(\boldsymbol{\mu g} / \mathrm{mL}) \text { of } \\
\text { Sorangiadenosine 1 }\end{array}$ & $\begin{array}{c}\mathrm{IC}_{\mathbf{5 0}}(\boldsymbol{\mu g} / \mathbf{m L}) \text { of } \\
\text { 2-hydroxysorangiadenosine 2 }\end{array}$ & $\begin{array}{c}\mathrm{IC}_{\mathbf{5 0}}(\boldsymbol{\mu g} / \mathbf{m L}) \text { of } \\
\text { Doxirubicin }\end{array}$ \\
\hline HCT-116 & 30.00 & 52.00 & 0.6 \\
KB-3-1 & 39.46 & $>111.1$ & 0.09 \\
\hline
\end{tabular}

\subsection{Identification of the 2-Hydroxysorangiadenosine Biosynthetic Gene Cluster}

According to retrobiosynthetic considerations, $\mathbf{1}$ and $\mathbf{2}$ are made of the building blocks adenosine (available from primary metabolism) and the eudesmane-type sesquiterpene, which can be generated from farnesyl pyrophosphate (FFP). Supplementation with sodium acetate ${ }^{13} \mathrm{C}_{2}$-representing the starting precursor for the mevalonate pathway-did not result in a significant mass shift in the isotopic pattern of $\mathbf{1}$ and $\mathbf{2}$ (Figures S1 and S4). Therefore, the previously characterized myxobacterial L-leucine degradation pathway (including the formation of isovaleryl-coenzyme A (CoA), 
dimethylacyrlyl-CoA and 3-methylglutaconyl-CoA) [27] that branches from the mevalonate-dependent isoprenoid biosynthesis pathway might be involved in the formation of $\mathbf{1}$ and $\mathbf{2}$. The observed mass shifts of $+5 \mathrm{Da},+10 \mathrm{Da}$ and $+14 \mathrm{Da}$ in the isotopic pattern of 1 and 2 upon dimethyl acrylic acid $\mathrm{d}_{6}$ supplementation suggest that the sesquiterpene scaffold originates from this myxobacterial isoprenoid pathway (Figures S2 and S5). In addition, genomic investigation of V. cumulatum MCy $10943^{\mathrm{T}}$ revealed the presence of all genes encoding the proteins which are required for the leucine degradation pathway [27] and the alternative biosynthesis of isovaleryl-CoA [28] (Figure S14 and Table S1). Corresponding mass shifts of $+4 \mathrm{Da}$ and $+5 \mathrm{Da}$ upon incorporation of adenosine monophosphate $\left({ }^{15} \mathrm{~N}_{5}\right)$ (Figures S3 and S6) underline that adenosine is transferred as a purine nucleoside to the eudesmadiene scaffold rather than being generated de novo. In conclusion, these feeding experiments proved that $\mathbf{1}$ and $\mathbf{2}$ are most likely generated from the building blocks isopentenyl diphosphate (IPP) or dimethylallyl diphosphate (DMAPP) and adenosine.

Based on the elucidated chemical structure of $\mathbf{1}$ and $\mathbf{2}$ along with the findings from feeding experiments, we propose both to be biosynthesized by farnesyl transferase (i), which produces FFP, a terpene cyclase (ii) which converts the generated FFP to a eudesmane-type sesquiterpene (eudesmadiene intermediate, see Figure S16) and a eudesmadiene transferase (iii) to transfer the adenosine building block onto the eudesmane-type sesquiterpene (Figure 4A). The mechanism to transfer adenosine, which is present in most microorganisms, might work via hydroamination (direct addition of ammonia or primary and secondary amines to non-activated alkenes and alkynes) or alkylation [29,30]. A last maturation step involves the hydroxylation of $\mathbf{1}$ leading to the herein described structure of 2. Since most bacterial terpene biosynthetic pathways involve tailoring steps through cytochrome P450 enzyme hydroxylations [31], we assume that the last tailoring step in the biosynthesis of 2 might be catalyzed as well by a cytochrome P450 enzyme (iv) (Figure 4A). This assumption is also supported by the fact that the secondary metabolome of $\mathrm{MCy} 10943^{\mathrm{T}}$ shows no signal corresponding to the sum formula of a hydroxylated eudesmadiene intermediate or intermedeol. In addition, three secondary metabolites with the mass of $205 \mathrm{~m} / \mathrm{z}$ and the sum formula $\mathrm{C}_{15} \mathrm{H}_{25}$ (which can be linked to non-hydroxylated eudesmadiene intermediates) are present in the crude extract of MCy10943 (Figure S16).
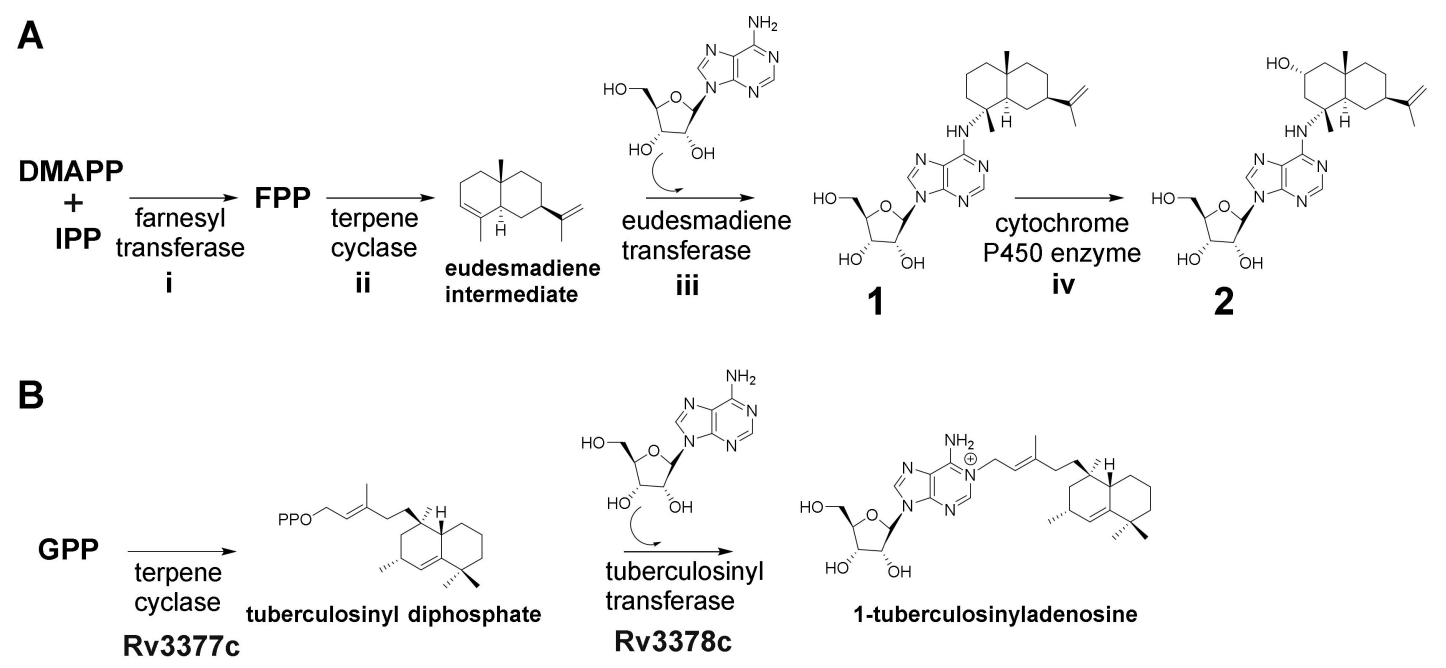

Figure 4. (A) Proposed biosynthetic route to 1 and 2 based on retrobiosynthetic considerations. (B) Biosynthesis of 1-tuberculosinyladenosine [32].

In contrast to the first, second and last biosynthetic steps, the catalytic reaction of a specific eudesmadiene transferase is unprecedented. This biosynthetic enzyme would act differently from classical cis-prenyl transferases by catalyzing the condensation of eudesmadiene pyrophosphate and adenosine to generate the previously discovered structure of $\mathbf{1}$. A similar reaction has been described 
for the biosynthesis of 1-tuberculosinyladenosine, where the second biosynthetic enzyme Rv3378c works as a tuberculosinyl transferase, catalyzing the condensation of tuberculosinyl pyrophosphate and adenosine to generate 1-tuberculosinyladenosine [32] (Figure 4B).

For this reason, genome sequence analysis was focused on gene clusters harboring genes encoding terpene or diterpene cyclases to identify the biosynthetic locus accounting for the production of $\mathbf{1}$ and 2. MCy $10943^{\mathrm{T}}$ harbors, according to the antibiotics and secondary metabolite analysis shell (antiSMASH) [33], nine putative terpene gene clusters (Table 3). In-silico genome sequence analysis of several myxobacterial strains (including alternative producers of $\mathbf{1}$ and $\mathbf{2}$ and strains with BGCs homologous to three terpene gene clusters found in $\mathrm{MCy} 10943^{\mathrm{T}}$ ) in combination with metabolomic profiling of corresponding crude extracts facilitated the identification of a candidate biosynthetic gene cluster (SI 2.3).

The candidate terpene gene cluster, No. 1, harbors all genes necessary for the formation of $\mathbf{1}$ and 2 (Table 3). Terpene gene cluster No. 1 contains 22 open reading frames (sora1-22) and comprises 27.920 bp (Figure 5A, Table 4). The myxobacterial strains Archangium violaceum $\mathrm{Cb}$ vi76 [34] and Archangium sp. Cb g35 [35] feature similar biosynthetic gene cluster organizations according to antiSMASH evaluation (however, these gene clusters are missing sora12, see below). The gene sora 9 encodes a terpene cyclase, which could produce the eudesmane-type sesquiterpene building block, while sora8 and sora12 presumably catalyze the transfer of the adenosine onto the terpene scaffold (Figure 5B). Both transferases share high mutual sequence similarity and probably exert the same catalytic function. Only the 2-hydroxysorangiadenosine gene cluster in V. cumulatum MCy10943 contains sora12, which might be the reason for the tremendously improved production in comparison to the identified alternative myxobacterial producers (SI 1.3).

Table 3. Biosynthetic gene clusters identified through antiSMASH analysis harboring a terpene cyclase.

\begin{tabular}{|c|c|c|c|c|c|}
\hline No. & Gene Cluster & Size (bp) & Location & Terpene Cyclase & Associated Biosynthesis ${ }^{1}$ \\
\hline 2 & Terpene & 42274 & 1269631-1311904 & $1 \times$ Type $\mathrm{I}$ & Geosmin $[36,37]$ \\
\hline 4 & Terpene & 41071 & 3447909-3488979 & $1 \times$ Type $I$ & \\
\hline 5 & Terpene & 40978 & $3603511-3644488$ & $1 \times$ Type I & Genome-Metab \\
\hline 6 & Terpene & 41041 & $4852259-4893299$ & $1 \times$ Type $I$ & Genome-Metab \\
\hline 8 & Terpene/TfuA-rel. & 50108 & 8404785-8454892 & $1 \times$ Type I & \\
\hline 9 & Terpene/RiPP & 78053 & 12603875-12681927 & $1 \times$ Type I & Geosmin $[36,37]$ \\
\hline
\end{tabular}

${ }^{1}$ Genome-Metab.; these gene clusters have been excluded to be responsible for the formation of $\mathbf{1}$ and $\mathbf{2}$, due to the genome-metabolome correlation (myxobacterial strains with homologues BGCs featured no detectable production of $\mathbf{1}$ or $\mathbf{2}$, see SI).

The identified type I terpene cyclase Sora9 contains all typical sequence motifs, such as the aspartate-rich motif DDxxxD, the pyrophosphate sensor (R), the NSE triad and the RY dimer [42]. In addition, terpene gene cluster No. 1 harbors several genes responsible for adenosine supply. In prokaryotes, adenosine can be formed either by salvage pathways or via de-novo synthesis, which starts from simple primary metabolites and forms inositol monophosphate (IMP) as a branch-point intermediate to form further guanosine monophosphate (GMP) and adenosine monophosphate (AMP), of which the later can be converted to adenosine via adenosine/deoxycytidine kinase or by the catalytic action of $5^{\prime}$-nucleotidase. In addition, adenosine can also be produced in the context of L-homocysteine metabolism, where $S$-adenosyl-homocysteine (SAH) is converted to adenosine via the SAH hydrolase. The gene for the conversion of $O$-acetyl-homoserine to L-homocysteine via an $\mathrm{O}$-acetylhomoserine sulfhydrylase (sora18) is located within the terpene gene cluster No. 1. The intermediate L-homocysteine can then subsequently be further converted by a vitamin $\mathrm{B}_{12}$-independent synthase (encoded by sora4) and a methionine synthase (encoded by sora13) to L-methionine. An ATP-dependent L-methionine adenosyltransferase catalyzes the production of $S$-adenosyl-methionine (SAM), which can be methylated by a SAM-dependent methyltransferase 
encoded by sora14. The catalytic product of Sora14, S-adenosyl-homocysteine (SAH), finally undergoes hydrolytic cleavage to yield adenosine, which can in turn be used as a building block for $\mathbf{1}$ and $\mathbf{2}$ (Figure 5C). These proteins further contribute to the availability of adenosine. In addition, these findings further support the assigned D-configuration of the ribose in 1 and $\mathbf{2}$ (see Section 2.1), since these genes are inseparably connected with the D-configured ribose, in particular the SAM-dependent methyltransferase Sora14. The truncated 2-hydroxysorangiadenosine BGC in the alternative producer Cystobacter sp. strain MCy9101 (SBCb004) also harbors sora13, sora14 and sora18 (Figure S18). Therefore, it seems likely that these encoded proteins are directly involved in adenosine supply for $\mathbf{1}$ and 2. As shown for the biosynthesis of 1-tuberculosinyladenosine, the gene responsible for the transfer of the adenosine scaffold is closely located to the terpene cyclase gene [32]. However, it cannot be excluded that the genes responsible for the generation of adenosine are located elsewhere in the genome.

In conclusion, these findings strongly support our conclusion that the identified BGC is involved in the proposed biosynthetic route leading to the formation of $\mathbf{1}$ and $\mathbf{2}$.

A

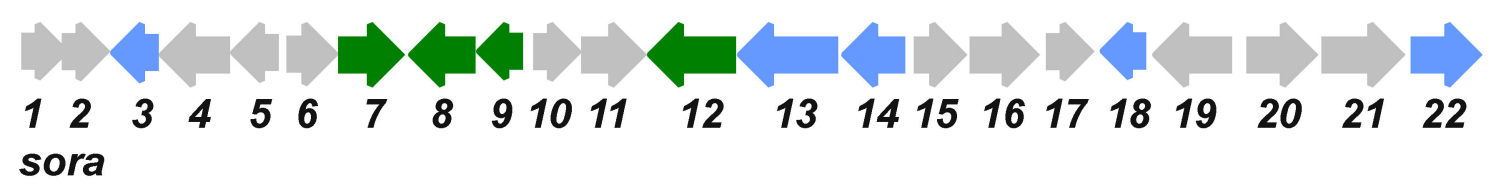

B

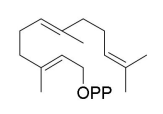

FPP
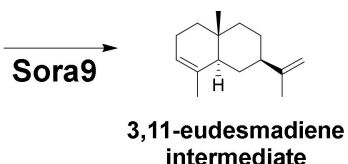

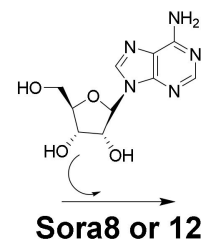

Sora8 or 12
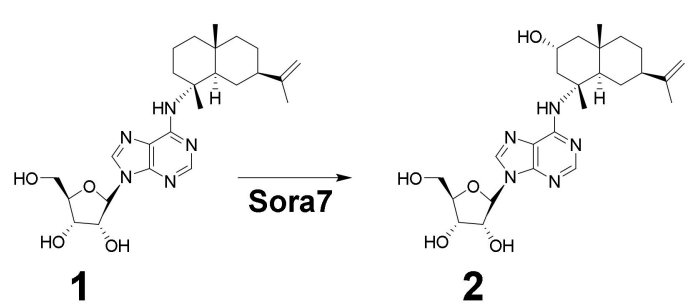

C
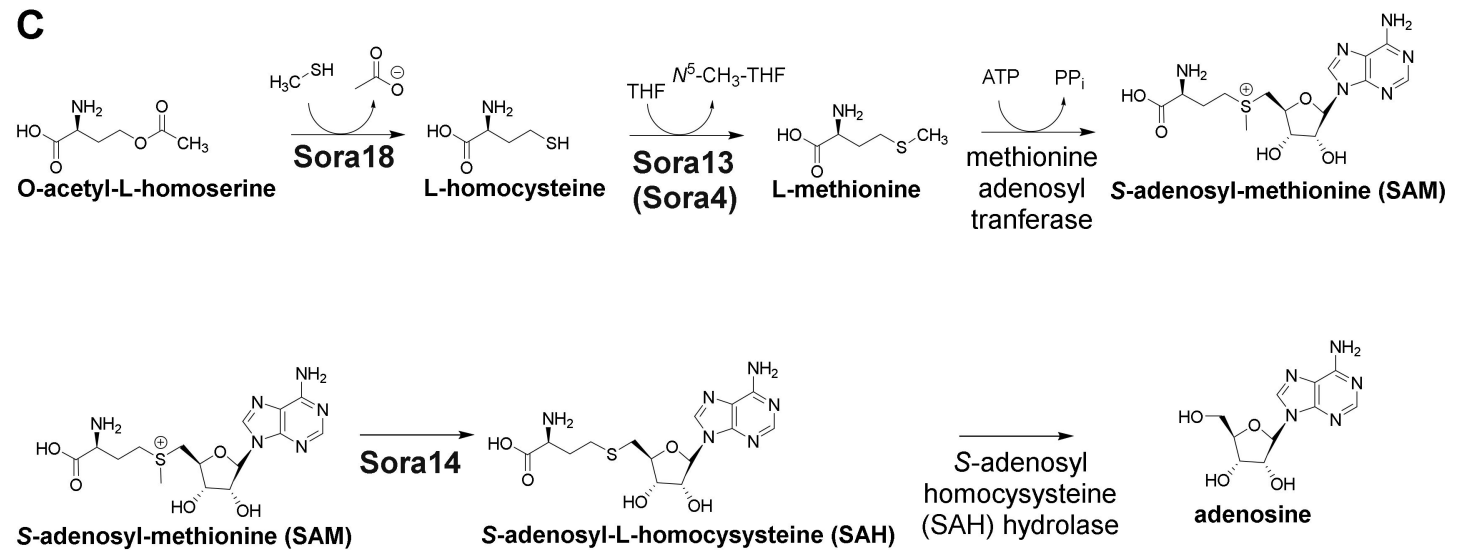

S-adenosyl-L-homocysysteine (SAH)
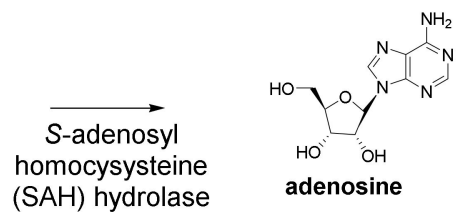

Figure 5. (A) Genetic organization of the candidate biosynthetic gene cluster responsible for the biosynthesis of sorangiadenosine (1) and 2-hydroxysorangiadenosine (2). (B) Proposed biosynthetic route leading to $\mathbf{1}$ and $\mathbf{2}$. (C) Catalyzed reactions to increase the supply of adenosine. 
Table 4. Predicted functions of the proteins encoded by the (2-hydroxy)sorangiadenosine biosynthetic gene cluster.

\begin{tabular}{ccccc}
\hline Gene & Size (aa) & Proposed Function & $\begin{array}{c}\text { Closest } \\
\text { Homologue }\end{array}$ & $\begin{array}{c}\text { Coverage/Similarity } \\
\text { (\%) }\end{array}$ \\
\hline sora1 & 378 & Oxidoreductase & WP_108075222 & $100 / 95.99$ \\
sora2 & 72 & Hypothetical protein & WP_108075223 & $100 / 93.90$ \\
sora3 & 173 & Hypothetical protein & WP_108075224 & $100 / 82.92$ \\
sora4 & 364 & Methionine synthase (MetE) & WP_108075225 & $100 / 95.87$ \\
sora5 & 304 & Hydrolase & WP_108075226 & $100 / 90.43$ \\
sora6 & 284 & Hypothetical protein & WP_108075227 & $95 / 92.25$ \\
sora7 & 457 & Cytochrome P450 enzyme & WP_108069092 & $98 / 95.67$ \\
sora8 & 518 & Eudesmadiene transferase & WP_047856205 & $99 / 80.31$ \\
sora9 & 333 & Terpene cyclase & WP_073564250 & $99.78 / 79.09$ \\
sora10 & 387 & Hypothetical protein & WP_095976240 & $91 / 56.91$ \\
sora11 & 609 & Sensory transducer & WP_146210122 & $92 / 74.69$ \\
sora12 & 509 & Eudesmadiene transferase & WP_108075230 & $100 / 73.80$ \\
sora13 & 1171 & Methionine synthase (MetH) & WP_108075232 & $100 / 97.61$ \\
sora14 & 299 & SAM-dependent methyltransferase & WP_108075233 & $100 / 97.32$ \\
sora15 & 292 & Patatin lipid acyl hydrolases & WP_108075234 & $100 / 98.97$ \\
sora16 & 375 & Dehydrogenase & WP_052519033 & $91 / 82.11$ \\
sora17 & 205 & Tet ${ }^{\mathrm{R}}$ transcriptional regulator & WP_073564266 & $100 / 79.62$ \\
sora18 & 147 & O-acetylhomoserine sulfhydrylase & WP_108075236 & $100 / 97.26$ \\
sora19 & 302 & Hypothetical protein & WP_108075237 & $100 / 88.70$ \\
sora20 & 449 & Thioredoxin & WP_140874099 & $99 / 54.81$ \\
sora21 & 279 & HP_158079939 & $100 / 77.34$ \\
sora22 & 630 & Pypothetical protein & WP_073564278 & $100 / 79.83$ \\
\hline
\end{tabular}

\section{Discussion}

The weak antibacterial myxobacterial sesquiterpene-nucleoside $\mathbf{1}$ was isolated from S. cellulosum KM1003 in 2008 [17]. Distinct structural features of 1, such as the heteroaromatic adenosine, the pentose sugar D-ribofuranose and the bicyclic sesquiterpene of eudesmane type are of particular biosynthetic interest, since they have not been reported for other myxobacterial natural products and are rare among other producers. The biosynthetic pathway and gene cluster leading to the formation of $\mathbf{1}$ have remained elusive. Unlike naturally occurring nucleotides and nucleoside natural products and terpenes, there are only few terpene-nucleoside/nucleotide hybrids known up-to date, in particular from microorganisms such as 1-tuberculosinyladenosine produced by Mycobacterium tuberculosis [32] or 2-methylthio- $N^{6}-\left(\Delta^{2}\right.$-isopentenyl)adenosine from E. coli [43]. The cytokines are described as plant-derived terpene-purine derivatives involved in cell growth and differentiation and act complementary with auxin as plant growth hormones [44,45]. The zeatins (adenine-type cytokinins like lupinic acid [46]) feature a hydroxylated isopentenyl building block on the N-6 position of adenosine. Furthermore, the agelasines [47,48], agelasimines [49] and asmarines [50] are terpene-purines originating from different genera of sponges (Agela sp., Raspailia sp.) which feature a diterpene attachment on the N-6 (and N-7 in case of asmarines) position of adenine [51].

In this study, we report the isolation and structure elucidation of the new natural product 2 alongside with the known derivative 1 from the myxobacterium $V$. cumulatum MCy $10943^{\mathrm{T}}$. For the first time, we provide biosynthetic insights leading to the production of these unique sesquiterpene-adenosine hybrids in myxobacteria. The presented discovery and in silico biosynthetic study paves the way for further genetic investigation of this intriguing pathway and the underlying production of these unique bioactive chemical scaffolds.

The development of genetic tools for the myxobacterium V. cumulatum MCy $10943^{\mathrm{T}}$ — which can be a difficult endeavor for myxobacterial strains [52]—would allow experimental correlation between the identified BGC and the production of $\mathbf{1}$ and $\mathbf{2}$. After genetic confirmation, the key biosynthetic genes could be heterologously expressed in the myxobacterial model host M. xanthus DK1622 in order 
to genetically engineer the biosynthetic pathway for an improved production rate or streamline the generation of new derivatives. In-depth biochemical investigation of the biosynthesis of $\mathbf{1}$ and $\mathbf{2}$ would be attained through recombinantly generated biosynthetic proteins to uncover single biosynthetic reactions or reconstitute the biosynthesis in vitro.

In conclusion, the presented discovery and the hypothesized biosynthetic pathway of $\mathbf{1}$ and $\mathbf{2}$ are essential prerequisites for further biosynthetic studies, production optimization and the generation of new sorangiadenosine derivatives.

\section{Materials and Methods}

\subsection{Applied Software, Sequence Analysis and Bioinformatics Methods}

DNA was isolated using a Qiagen Genomic-tip 100/G (Qiagen, Hilden, Germany) according to the instructions of the manufacturer. A SMRTbell ${ }^{\mathrm{TM}}$ template library was prepared according to the instructions from Pacific Biosciences (Pacific Biosciences, Menlo Park, CA, USA), following the Procedure and Checklist-Greater Than $10 \mathrm{~kb}$ Template Preparation. Briefly, for preparation of $15 \mathrm{~kb}$ libraries, $8 \mu \mathrm{g}$ genomic DNA was sheared using g-tubes ${ }^{\mathrm{TM}}$ from Covaris (Covaris, Woburn, MA, USA), according to the manufacturer's instructions. DNA was end-repaired and ligated overnight to hairpin adapters applying components from the DNA/Polymerase Binding Kit P6 from Pacific Biosciences (Pacific Biosciences, Menlo Park, CA, USA). Reactions were carried out according to manufacturer's instructions. BluePippin ${ }^{\mathrm{TM}}$ Size-Selection to greater than $7 \mathrm{~kb}$ was performed according to the manufacturer's instructions (Sage Science, Beverly, MA, USA). Conditions for annealing of sequencing primers and binding of polymerase to purified SMRTbell ${ }^{\mathrm{TM}}$ template were assessed with the Calculator in RS Remote, Pacific Biosciences (Pacific Biosciences, Menlo Park, CA, USA). Two SMRT cells were sequenced on the PacBio RSII (Pacific Biosciences, Menlo Park, CA, USA), taking 240 min movies.

The neutral sum formulas of the identified two target masses $\left(\mathrm{C}_{25} \mathrm{H}_{37} \mathrm{~N}_{5} \mathrm{O}_{4}\right.$ corresponding to 1 and $\mathrm{C}_{25} \mathrm{H}_{37} \mathrm{~N}_{5} \mathrm{O}_{5}$ corresponding to 2) were used to search in several chemical structure databases (SciFinder, Dictionary of Natural Products, ChemSpider, PubChem, ChEMBL, ZINC and Super Natural II). The Vitiosangium cumulatum MCy $10943^{\mathrm{T}}$ genome was screened for secondary metabolite BGCs using the antiSMASH 5.0 [33] online tool and the software Geneious Prime ${ }^{\circledR}$ (Biomatters Ltd., Auckland, New Zealand, 2020.0.5) [53]. The nucleotide or amino acid sequence of interest was aligned with the basic local alignment search tool (BLAST) against our in-house genome database or the publicly available nucleotide database, in order to find homologous genes or proteins. The functional prediction of ORFs was performed by either using protein blast and/or blastx programs and Pfam [54]. The nucleotide sequence of the 2-hydroxysorangiadenosine BGC originating from MCy $10943^{\mathrm{T}}$ has been deposited in GenBank and is accessible under the accession number MT520811. The same nucleotide sequence will be implemented in the Minimum Information about a Biosynthetic Gene cluster (MIBiG) database. Further information concerning gene sequences can be found in the Supplementary Information.

\subsection{Maintenance of Bacterial Cultures and Feeding Experiments with Stable Isotope-Labeled Building Blocks}

Vitiosangium cumulatum MCy $10943^{\mathrm{T}}$ was routinely cultivated at $30{ }^{\circ} \mathrm{C}$ in $\mathrm{CyHv} 3$ medium or agar plates ( $0.2 \%$ soytone (BD), $0.3 \%$ casitone (BD), $0.2 \%$ glucose, $0.8 \%$ soluble starch (Roth), $0.15 \%$ yeast extract (BD), $0.1 \% \mathrm{CaCl}_{2} \times 2 \mathrm{H}_{2} \mathrm{O}, 0.1 \% \mathrm{MgSO}_{4} \times 7 \mathrm{H}_{2} \mathrm{O}, 50 \mathrm{mM} \mathrm{HEPES} \mathrm{(for} \mathrm{agar} \mathrm{plate} \mathrm{cultures}$ $15 \mathrm{~g} / \mathrm{L}$ agar) adjusted $\mathrm{pH}$ to 7.2 with $10 \mathrm{~N} \mathrm{KOH}$ before autoclaving, added after autoclaving $8 \mathrm{mg} / \mathrm{L}$ Fe-EDTA). Liquid cultures were grown in Erlenmeyer flasks on an orbital shaker at 180 rpm for 3-6 days. Feeding experiments were performed by cultivating the strain in $20 \mathrm{~mL}$ CyHv3 broth using $100 \mu \mathrm{L}$ inoculum $(0.5 \%$ inoculum volume). The cultures were supplemented with $1 \mathrm{~mL}(v / v)$ sterile amberlite resin XAD-16 (Sigma-Aldrich Chemie $\mathrm{GmbH}$, Taufkirchen, Germany) and fed for five consecutive days with $20 \mu \mathrm{L}$ of a $0.1 \mathrm{M}$ solution of either sodium acetate $\left({ }^{13} \mathrm{C}_{2}\right)$, sodium dimethyl acrylic acid $\left(\mathrm{d}_{6}\right)$ or adenosine monophosphate $\left({ }^{15} \mathrm{~N}_{5}\right)$ at $30{ }^{\circ} \mathrm{C}$, at $180 \mathrm{rpm}$. The combined cells and resin were 
harvested by centrifugation after seven days of incubation before extraction. The supernatant was discarded, whereas the combined cells and resin were extracted with a mixture of $25 \mathrm{~mL}$ methanol $(\mathrm{MeOH})$ and $25 \mathrm{~mL}$ acetone, stirred for $2 \mathrm{~h}$ and filtered through filter paper, and the solvent of the extracts was removed under vacuum. The re-dissolved extracts $(2 \mathrm{~mL})$ were diluted with $\mathrm{MeOH}$ $(1: 3$ (extract/MeOH, $v / v)$ and centrifuged, and the supernatant was subjected to HPLC-MS analysis as described further below.

\subsection{Analysis of Secondary Metabolism of Broth Extracts}

The secondary metabolism of broth extracts was analyzed by high-performance liquid chromatography-high-resolution electrospray ionization-diode array-detector-mass spectrometry (HPLC-HRESI-DAD-MS) on a maXis 4G mass spectrometer (Bruker Daltonics, Billerica, MA, USA) coupled with a Dionex UltiMate 3000 Rapid Separation (RS)LC system (Thermo Fisher Scientific, Waltham, MA, USA) using a BEH C18 column $(100 \times 2.1 \mathrm{~mm}, 1.7 \mu \mathrm{m})$ (Waters, Eschborn, Germany) with a gradient of $5-95 \%$ acetonitrile $(\mathrm{ACN})+0.1 \%$ formic acid (FA) in $\mathrm{H}_{2} \mathrm{O}+0.1 \% \mathrm{FA}$ at $0.6 \mathrm{~mL} / \mathrm{min}$ and $45^{\circ} \mathrm{C}$ over $18 \mathrm{~min}$ with ultraviolet (UV) detection by a DAD at 200-600 $\mathrm{nm}$. Mass spectra were acquired from 150 to $2000 \mathrm{~m} / \mathrm{z}$ at $2 \mathrm{~Hz}$. Detection was performed in the positive MS mode. The plugin for Chromeleon Xpress (Thermo Fisher Scientific, Waltham, MA, USA, version 6.8) was used for operation of the Dionex UltiMate 3000 RSLC system. HyStar (Bruker Daltonics, Billerica, MA, USA, version 3.2) was used to operate on the maXis $4 \mathrm{G}$ mass spectrometer system. HPLC-MS mass spectra were analyzed with DataAnalysis (Bruker Daltonics, Billerica, MA, USA, version 4.2).

\subsection{Compound Isolation}

At the end of fermentation $(60 \mathrm{~L})$, wet cell mass and adsorbent resin XAD-16 were harvested by centrifugation and extracted three times with $2 \mathrm{~L}$ of acetone. The extract was dried under vacuum resulting in $7.68 \mathrm{~g}$ of crude extract. The crude extract was dissolved in $2 \mathrm{~L} \mathrm{MeOH}$ and partitioned using $2 \mathrm{~L}$ hexane solvent. The MeOH layer was dried (5.34 g) and dissolved in $2 \mathrm{~L}$ deionized water followed by further partitioning using chloroform $\left(\mathrm{CHCl}_{3}\right)$. The $\mathrm{CHCl}_{3}$ layer was dried under vacuum to yield $3.95 \mathrm{~g}$ of extract. The $3.95 \mathrm{~g}$ of $\mathrm{CHCl}_{3}$ extract was subjected to flash chromatography on a Isolera ${ }^{\mathrm{TM}}$ One (Biotage, Uppsala, Sweden) with a SNAP $100 \mathrm{~g}$ column packed with silica gel (60 A, 70-230 mesh, 63-200 $\mu \mathrm{m}$ ), using 100\% n-hexane (5 column volume (CV)), 95\% n-hexane /ethyl acetate (EA) (5 CV), 95\% $n$-hexane/EA to 100\% EA (25 CV), 100\% EA (5 CV), 95\% EA /MeOH gradient as eluents. The flow rate was $50 \mathrm{~mL} / \mathrm{min}$ while the UV/Vis absorption was set at $260 \mathrm{~nm}$ and $320 \mathrm{~nm}$. Fractions of $45 \mathrm{~mL}$ were collected and measured on a Dionex UltiMate 3000 RSLC system (Thermo Fisher Scientific, Waltham, MA, USA) coupled to an amaZon ion trap MS (Bruker Daltonics, Billerica, MA, USA) using a BEH $\mathrm{C} 18,100 \times 2.1 \mathrm{~mm}, 1.7 \mu \mathrm{m}$ dp column equipped with a C18 precolumn (Waters, Eschborn, Germany) to detect the fractions containing 1 or $\mathbf{2}$. Fractions 83-95 were pooled and dried under vacuum to yield 1.23 g extract. Purification of sample was done using an UltiMate 3000 semi-preparative system coupled to a Thermo Scientific Dionex UltiMate 3000 Series automated fraction collector (Bruker Daltonics, Billerica, MA, USA). Separation was performed on a C18 Phenomenex Luna (100, $5 \mu \mathrm{m}$, $10 \times 250 \mathrm{~mm})$ LC column (Phenomenex, Torrance, CA, USA) and eluted with water $(0.1 \% \mathrm{FA})$ as solvent $\mathbf{A}$ and $\mathrm{ACN}(0.1 \% \mathrm{FA})$ as solvent $\mathbf{B}$ at a flow rate of $5 \mathrm{~mL} / \mathrm{min}$. The initial gradient was held at $5 \% \mathrm{ACN}$ for $2 \mathrm{~min}$ and then elevated to $60 \% \mathrm{ACN}$ within $5 \mathrm{~min}$. This was followed by an increase from $61 \%$ to $70 \%$ ACN during a period of $25 \mathrm{~min}$ and then to $95 \%$ ACN within 5 min. The gradient was held at $95 \% \mathrm{ACN}$ for $2 \mathrm{~min}$ and then ramped back to 5\% ACN over $1 \mathrm{~min}$. The column was re-equilibrated at $5 \% \mathrm{ACN}$ for $5 \mathrm{~min}$. Detection of the sesquiterpene-nucleosides was facilitated via mass spectrometry on the Agilent 1100 series (Agilent Technologies, Santa Clara, CA, USA) coupled to the HCT 3D ion trap (Bruker Daltonics, Billerica, MA, USA) or with a UV detector on the Dionex UltiMate 3000 RSLC system by UV absorption at $220 \mathrm{~nm}, 260 \mathrm{~nm}, 320 \mathrm{~nm}$ and $400 \mathrm{~nm}$. The pure compounds were subsequently dried by lyophilization and resulted in $4.91 \mathrm{mg}$ of compound 2 and $3.88 \mathrm{mg}$ of compound 1 at a retention time of $18.23 \mathrm{~min}$ and $22.14 \mathrm{~min}$, respectively. 


\subsection{NMR-Based Structure Elucidation, Chiroptical and CD Measurement}

The chemical structures of $\mathbf{1}$ and $\mathbf{2}$ were determined via multidimensional NMR analysis. ${ }^{1} \mathrm{H}-\mathrm{NMR}$, ${ }^{13} \mathrm{C}-\mathrm{NMR}$ and 2D spectra were recorded at $500 \mathrm{MHz}(1 \mathrm{H}) / 175 \mathrm{MHz}\left({ }^{13} \mathrm{C}\right)$, conducting an Ascend 500 spectrometer using a cryogenically cooled triple resonance probe (Bruker Biospin, Rheinstetten, Germany). Samples were dissolved in methanol- $\mathrm{d}_{4}$. Chemical shifts are reported in ppm relative to tetramethylsilane; the solvent was used as the internal standard.

Chiroptical measurements of $\mathbf{1}$ and $\mathbf{2}$ in $\mathrm{MeOH}\left([\alpha]_{\mathrm{D}}\right)$ were obtained on a Model 341 polarimeter (PerkinElmer Inc., Waltham, MA, USA) in a $100 \times 2 \mathrm{~mm}$ cell at $20^{\circ} \mathrm{C}$. Circular dichroism measurements were performed for 2 at $1.0 \mathrm{mM}$ in $\mathrm{MeOH}(190-400 \mathrm{~nm})$ with the J-1500 CD spectrophotometer (JASCO, Easton, MD, USA).

\subsection{Bioactivity Profiling}

Standard sterile microbiological techniques were maintained throughout. All microorganisms and cell lines were handled according to standard procedures and were obtained from the German Collection of Microorganisms and Cell Cultures (Deutsche Sammlung für Mikroorganismen und Zellkulturen, DSMZ) or were part of our internal strain collection and were cultured under conditions recommended by the depositor. Both $\mathbf{1}$ and $\mathbf{2}$ were tested in microbroth dilution assays on the following panel of microorganisms: Escherichia coli WT (DSM 1116), E. coli JW0451-2 (acrB-efflux pump deletion mutant of E. coli BW25113), Pseudomonas aeruginosa PA14, Bacillus subtilis DSM 10, Mycobacterium smegmatis MC M $^{2} 155$ (DSM 43756), Staphylococcus aureus Newman, Candida albicans DSM 1665, Citrobacter freundii DSM 30039, Pichia anomala DSM 6766 and Acinetobacter baumannii DSM 30007. For microbroth dilution assays, overnight cultures were prepared from cryogenically preserved cultures and were diluted to achieve a final inoculum of $10^{4}-10^{5}$ colony-forming units $(\mathrm{cfu}) / \mathrm{mL}$. Serial dilutions of compounds were prepared in sterile 96-well plates in the respective test medium. The cell suspension was added and microorganisms were grown for $18-48 \mathrm{~h}$ at either $30^{\circ} \mathrm{C}$ or $37^{\circ} \mathrm{C}$. Growth inhibition was evaluated by visual inspection, and given MIC values are the lowest concentrations of antibiotic at which no visible growth was observed.

To evaluate the cytotoxic capabilities of $\mathbf{1}$ and 2, HCT-116 (human colon carcinoma cell line, DSMZ No. ACC 581) and KB-3-1 (cervix carcinoma cell line, DSMZ No. ACC 158) cells were seeded at $6 \times 10^{3}$ cells per well of 96 -well plates in $180 \mu \mathrm{L}$ complete medium and treated with $\mathbf{1}$ or $\mathbf{2}$ in serial dilution after $2 \mathrm{~h}$ equilibration. After five days of incubation, $20 \mu \mathrm{L}$ of $5 \mathrm{mg} / \mathrm{mL}$ MTT (thiazolyl blue tetrazolium bromide) in phosphate-buffered saline (PBS) was added per well and it was further incubated for $2 \mathrm{~h}$ at $37^{\circ} \mathrm{C}$. The medium was discarded, and cells were washed with $100 \mu \mathrm{L}$ PBS before adding $100 \mu \mathrm{L}$ isopropanol/10 N HCl (250:1) in order to dissolve formazan granules. The absorbance at $570 \mathrm{~nm}$ was measured using the microplate reader Infinite ${ }^{\circledR}$ M200Pro (Tecan Group Ltd., Männedorf, Switzerland), and cell viability was expressed as a percentage relative to the respective $\mathrm{MeOH}$ control. $\mathrm{IC}_{50}$ values were determined by sigmoidal curve fitting.

Supplementary Materials: The following are available online, Figure S1: Partial ESI + MS spectra for sorangiadenosine (1) supplemented with sodium acetate $\left({ }^{13} \mathrm{C}_{2}\right)$ (bottom) and culture broth without precursor feeding as control (top). Figure S2: Partial ESI + MS spectra for sorangiadenosine (1) supplemented with sodium dimethyl acrylic acid $\left(\mathrm{d}_{6}\right)$ (bottom) and culture broth without precursor feeding as control (top). Figure S3: Partial ESI + MS spectra for sorangiadenosine (1) supplemented with adenosine monophosphate $\left({ }^{15} \mathrm{~N}_{5}\right)$ (bottom) and culture broth without precursor feeding as control (top). Figure S4: Partial ESI + MS spectra for 2-hydroxysorangiadenosine (2) supplemented with sodium acetate $\left({ }^{13} \mathrm{C}_{2}\right)$ (bottom) and culture broth without precursor feeding as control (top). Figure S5: Partial ESI + MS spectra for 2-hydroxysorangiadenosine (2) supplemented with sodium dimethyl acrylic acid $\left(\mathrm{d}_{6}\right)$ (bottom) and culture broth without precursor feeding as control (top). Figure S6: Partial ESI + MS spectra for 2-hydroxysorangiadenosine (2) supplemented with adenosine monophosphate $\left({ }^{15} \mathrm{~N}_{5}\right)$ (bottom) and culture broth without precursor feeding as control (top). Figure S7: Partial ESI + MS spectra for sorangiadenosine (1). Figure S8: Partial ESI + MS spectra for 2-hydroxysorangiadenosine (2). Figure S9: HPLC-MS EICs of crude extracts of Cystobacter sp. MCy9101 (top) and Vitiosangium cumulatum MCy10943 ${ }^{\mathrm{T}}$ (bottom). EIC: Extracted ion chromatogram, green: $488.2873 \mathrm{~m} / \mathrm{z}$, with a width of $7.9 \mathrm{ppm}$, 2-hydroxysorangiadenosine $[\mathrm{M}+\mathrm{H}]^{+}$. Figure S10: HPLC-MS EICs of crude extracts of Cystobacter sp. MCy9101 
(top) and Vitiosangium cumulatum MCy10943 ${ }^{\mathrm{T}}$ (bottom). EIC: Extracted ion chromatogram, blue: $472.2924 \mathrm{~m} / \mathrm{z}$, with a width of $7.9 \mathrm{ppm}$, sorangiadenosine $[\mathrm{M}+\mathrm{H}]^{+}$. Figure S11: HPLC-MS EICs of crude extracts of Vitiosangium cumulatum MCy10943 ${ }^{\mathrm{T}}$, Cystobacter fuscus DSM 2262, Cystobacter fuscus $\mathrm{Cb}$ fe15 and Cystobacter ferrugineus $\mathrm{Cb}$ fe23. EIC: Extracted ion chromatogram, green: $488.2873 \mathrm{~m} / \mathrm{z}$, with a width of $7.9 \mathrm{ppm}$, 2-hydroxysorangiadenosine $[\mathrm{M}+\mathrm{H}]^{+}$. Figure S12: HPLC-MS EICs of crude extracts of Vitiosangium cumulatum MCy10943 ${ }^{\mathrm{T}}$, Cystobacter fuscus DSM 2262, Cystobacter fuscus $\mathrm{Cb}$ fe15 and Cystobacter ferrugineus $\mathrm{Cb}$ fe23. EIC: Extracted ion chromatogram, green: $472.2924 \mathrm{~m} / \mathrm{z}$, with a width of $7.9 \mathrm{ppm}$, sorangiadenosine $[\mathrm{M}+\mathrm{H}]^{+}$. Figure S13: $\mathrm{CD}$ spectrum of 2-hydroxysorangiadenosine at $1.0 \mathrm{mM}$ in $\mathrm{MeOH}$ in the area 190-400 nm, shows two negative cotton effect bands at $215 \mathrm{~nm}$ and $260 \mathrm{~nm}$ (top). Figure S14: Leucine degradation pathway (grey boxes) and the alternative biosynthesis of isovaleryl CoA observed in Myxococcus xanthus DK1622. Proteins are listed in Table S1. Figure S15: 1,10 -cyclization and 1,11-cyclization from farnesylpyrophosphate (FFP) yield the $(E, E)$-germacrenyl cation, which is the proposed precursor for the generation of eudesmane-type sesquiterpene required for the biosynthesis of 1 and 2 or $(E, E)$-humulyl cation, respectively. Both enantiomers of the $(E, E)$-germacrenyl cation can be formed. (B) Isomerization mechanism of FFP to nerolidyl diphosphate (NPP). (C) NPP can be cyclized to a bisabolyl cation via 1,6-cyclization, to the cycloheptenyl cation via 1,7-cyclization, to the $(E, Z)$-germacrenyl cation via a 1,10-cyclization or to the $(E, Z)$-humulyl cation via a 1,11-cyclization. Both enantiomeric products of the 1,6-cyclization, 1,10-cyclization and 1,11-cyclization can be generated. Figure S16: (A) Proposed start of the sesquiterpene part during the biosynthesis of sorangiadenosine yielding the intermediate germacrenyl-cation. (B) Possible formation of intermedeol from the intermediate germacrenyl-cation. (C) Proposed formation of the different eudesmadiene building blocks. Figure S17: HPLC-MS EIC of Vitiosangium cumulatum MCy10943 crude extract. EIC: Extracted ion chromatogram, black: $205.1956 \mathrm{~m} / \mathrm{z}$, with a width of 7.9 ppm, proposed non-hydroxylated eudesmadiene intermediates $[\mathrm{M}+\mathrm{H}]^{+}$. Figure S18: Genetic organization of the truncated 2-hydroxysorangiadenosine BGC from Cystobacter sp. strain MCy9101 (SBCb004). Figure S19: Chemical structure and numbering of sorangiadenosine (1) and 2-hydroxysorangiadenosine (2). Figure S20: ${ }^{1} \mathrm{H}-\mathrm{NMR}$ spectrum of sorangiadenosine (1) in methanol- $\mathrm{d}_{4}$. Figure S21: ${ }^{13} \mathrm{C}-\mathrm{NMR}$ spectrum of sorangiadenosine (1) in methanol- $\mathrm{d}_{4}$. Figure S22: HSQC spectrum of sorangiadenosine (1) in methanol- $\mathrm{d}_{4}$. Figure S23: DQF-COSY spectrum of sorangiadenosine (1) in methanol- $\mathrm{d}_{4}$. Figure S24: HMBC spectrum of sorangiadenosine (1) in methanol- $\mathrm{d}_{4}$. Figure S25: ${ }^{1} \mathrm{H}$ NMR spectrum of 2-hydroxysorangiadenosine (2) in methanol- $\mathrm{d}_{4}$. Figure S26: ${ }^{13} \mathrm{C}$ NMR spectrum of 2-hydroxysorangiadenosine (2) in methanol- $\mathrm{d}_{4}$. Figure S27: HSQC spectrum of 2-hydroxysorangiadenosine (2) in methanol- $\mathrm{d}_{4}$. Figure S28: DQF-COSY spectrum of 2-hydroxysorangiadenosine (2) in methanol- $\mathrm{d}_{4}$. Figure S29: HMBC spectrum of 2-hydroxysorangiadenosine (2) in methanol- $\mathrm{d}_{4}$. Figure S30: ROESYphpr spectrum No. 1 of 2-hydroxysorangiadenosine (2) in methanol- $\mathrm{d}_{4}$. Figure S31: ROESYphpr spectrum No. 2 of 2-hydroxysorangiadenosine (2) in methanol- $\mathrm{d}_{4}$. Figure S32: ROESYphpr spectrum 3 of 2-hydroxysorangiadenosine (2) in methanol-d $\mathrm{d}_{4}$. Figure S33: ROESYphpr spectrum 4 (expanded region) of 2-hydroxysorangiadenosine (2) in methanol- $\mathrm{d}_{4}$. Table S1: Proteins involved in leucine degradation and in the alternative isovaleryl-CoA biosynthesis in Myxococcus xanthus DK1622 and their identified homologues in Vitiosangium cumulatum MCy10943 ${ }^{\mathrm{T}}$. Table S2: NMR spectroscopic data for sorangiadenosine (1) in methanol- $\mathrm{d}_{4}$. Table S3: NMR spectroscopic data for 2-hydroxysorangiadenosine (2) methanol- $\mathrm{d}_{4}$.

Author Contributions: Conceptualization and writing-D.A.O. and J.J.H.; Compound isolation and structure elucidation-D.A.O.; Biosynthetic investigation and comparative metabolome analysis-J.J.H.; large-scale fermentation, feeding experiments and preparation of the strain for genome sequencing-R.G.; genome sequencing and assembly-C.S. and J.O., Supervision, conceptualization and writing of publication-R.M. All authors have read and agreed to the published version of the manuscript.

Funding: Joachim J. Hug acknowledges funding from a PhD fellowship of Boehringer Ingelheim Fonds. Dorothy A. Okoth acknowledges funding from a Humboldt Foundation postdoctoral fellowship.

Acknowledgments: The authors thank Stefanie Schmidt, Irene Kochems, and Victoria Schmitt for performing bioactivity assays, Bettina Ehlert and Carola Berg for excellent technical assistance with sequencing, Nestor Zaburannyi and Boyke Bunk for bioinformatic support. Research in Rolf Müller's laboratory is funded by the Deutsche Forschungsgemeinschaft (DFG), the Bundesministerium für Bildung und Forschung (BMBF) and the Deutsches Zentrum für Infektionsforschung Standort Hannover-Braunschweig.

Conflicts of Interest: The authors declare no conflict of interest.

\section{References}

1. Munoz-Dorado, J.; Marcos-Torres, F.J.; Garcia-Bravo, E.; Moraleda-Munoz, A.; Perez, J. Myxobacteria: Moving, Killing, Feeding, and Surviving Together. Front. Microbiol. 2016, 7, 2475. [CrossRef] [PubMed]

2. Cao, P.; Dey, A.; Vassallo, C.N.; Wall, D. How Myxobacteria Cooperate. J. Mol. Biol. 2015, 427, $3709-3721$. [CrossRef] [PubMed]

3. Herrmann, J.; Fayad, A.A.; Müller, R. Natural products from myxobacteria: Novel metabolites and bioactivities. Nat. Prod. Rep. 2017, 34, 135-160. [CrossRef] [PubMed] 
4. Gerth, K.; Bedorf, N.; Irschik, H.; Höfle, G.; Reichenbach, H. The soraphens: A family of novel antifungal compounds from Sorangium cellulosum (Myxobacteria). I. Soraphen $\mathrm{A}_{1 \alpha}$ : Fermentation, isolation, biological properties. J. Antibiot. 1994, 47, 23-31. [CrossRef]

5. Baumann, S.; Herrmann, J.; Raju, R.; Steinmetz, H.; Mohr, K.I.; Hüttel, S.; Harmrolfs, K.; Stadler, M.; Müller, R. Cystobactamids: Myxobacterial topoisomerase inhibitors exhibiting potent antibacterial activity. Angew. Chem. Int. Ed. 2014, 53, 14605-14609. [CrossRef]

6. Gerth, K.; Steinmetz, H.; Höfle, G.; Jansen, R. Chlorotonil A, a Macrolide with a Unique gem-Dichloro-1,3-dione Functionality from Sorangium cellulosum, So ce1525. Angew. Chem. Int. Ed. Engl. 2008, 47, 600-602. [CrossRef]

7. Plaza, A.; Garcia, R.; Bifulco, G.; Martinez, J.P.; Hüttel, S.; Sasse, F.; Meyerhans, A.; Stadler, M.; Müller, R. Aetheramides $\mathrm{A}$ and $\mathrm{B}$, potent HIV-inhibitory depsipeptides from a myxobacterium of the new genus "Aetherobacter". Org. Lett. 2012, 14, 2854-2857. [CrossRef]

8. Sasse, F.; Steinmetz, H.; Heil, J.; Höfle, G.; Reichenbach, H. Tubulysins, new cytostatic peptides from myxobacteria acting on microtubuli. Production, isolation, physico-chemical and biological properties. J. Antibiot. 2000, 53, 879-885. [CrossRef]

9. Ullrich, A.; Chai, Y.; Pistorius, D.; Elnakady, Y.A.; Herrmann, J.E.; Weissman, K.J.; Kazmaier, U.; Müller, R. Pretubulysin, a potent and chemically accessible tubulysin precursor from Angiococcus disciformis. Angew. Chem. Int. Ed. Engl. 2009, 48, 4422-4425. [CrossRef]

10. Dickschat, J.S.; Wenzel, S.C.; Bode, H.B.; Müller, R.; Schulz, S. Biosynthesis of volatiles by the myxobacterium Myxococcus xanthus. ChemBioChem 2004, 5, 778-787. [CrossRef]

11. Dickschat, J.S.; Bode, H.B.; Wenzel, S.C.; Müller, R.; Schulz, S. Biosynthesis and identification of volatiles released by the myxobacterium Stigmatella aurantiaca. ChemBioChem 2005, 6, 2023-2033. [CrossRef] [PubMed]

12. Dickschat, J.S.; Bode, H.B.; Mahmud, T.; Müller, R.; Schulz, S. A novel type of geosmin biosynthesis in myxobacteria. J. Org. Chem. 2005, 70, 5174-5182. [CrossRef] [PubMed]

13. Brock, N.L.; Ravella, S.R.; Schulz, S.; Dickschat, J.S. A Detailed View of 2-Methylisoborneol Biosynthesis. Angew. Chem. Int. Ed. Engl. 2013, 52, 2100-2104. [CrossRef] [PubMed]

14. Dickschat, J.S.; Nawrath, T.; Thiel, V.; Kunze, B.; Müller, R.; Schulz, S. Biosynthesis of the off-flavor 2-methylisoborneol by the myxobacterium Nannocystis exedens. Angew. Chem. Int. Ed. Engl. 2007, 46, 8287-8290. [CrossRef]

15. Schifrin, A.; Ly, T.T.; Günnewich, N.; Zapp, J.; Thiel, V.; Schulz, S.; Hannemann, F.; Khatri, Y.; Bernhardt, R. Characterization of the Gene Cluster CYP264B1-geoA from Sorangium cellulosum So ce56: Biosynthesis of (+)-Eremophilene and Its Hydroxylation. ChemBioChem 2015, 16, 337-344. [CrossRef]

16. Schifrin, A.; Khatri, Y.; Kirsch, P.; Thiel, V.; Schulz, S.; Bernhardt, R. A single terpene synthase is responsible for a wide variety of sesquiterpenes in Sorangium cellulosum So ce56. Org. Biomol. Chem. 2016, 14, 3385-3393. [CrossRef]

17. Ahn, J.W.; Jang, K.H.; Chung, S.C.; Oh, K.B.; Shin, J. Sorangiadenosine, a new sesquiterpene adenoside from the myxobacterium Sorangium cellulosum. Org. Lett. 2008, 10, 1167-1169. [CrossRef]

18. Awal, R.P.; Garcia, R.; Gemperlein, K.; Wink, J.; Kunwar, B.; Parajuli, N.; Müller, R. Vitiosangium cumulatum gen. nov., sp. nov. and Vitiosangium subalbum sp. nov., soil myxobacteria, and emended descriptions of the genera Archangium and Angiococcus, and of the family Cystobacteraceae. Int. J. Syst. Evol. Microbiol. 2017, 67, 1422-1430. [CrossRef]

19. Mai, N.T.; Cuc, N.T.; Quang, T.H. Chemical constituents of Datura metel L. Viet. J. Chem. 2017, 55, 188-195.

20. Ciuffreda, P.; Casati, S.; Manzocchi, A. Complete ${ }^{1} \mathrm{H}$ and ${ }^{13} \mathrm{C}$ NMR spectral assignment of $\alpha$ - and $\beta$-adenosine, 2'-deoxyadenosine and their acetate derivatives. Magn. Reson. Chem. 2007, 45, 781-784. [CrossRef]

21. Nakamukai, S.; Ise, Y.; Ohtsuka, S.; Okada, S.; Matsunaga, S. Isolation and identification of $N^{6}$-isopentenyladenosine as the cytotoxic constituent of a marine sponge Oceanapia sp. Biosci. Biotechnol. Biochem. 2019, 83, 1985-1988. [CrossRef] [PubMed]

22. Brunner, W.C.; Maestre, M.F. Circular dichroism of some mononucleosides. Biopolymers 1975, 14, 555-565. [CrossRef] [PubMed]

23. Moore, D.S. Circular dichroism of nucleic acid monomers. I. Calculated adenosine and 2' -deoxyadenosine CD spectra. Biopolymers 1980, 19, 1017-1038. [CrossRef]

24. Miles, D.W.; Farmer, M.; Eyring, H. Calculations of the circular dichroism of adenosine derivatives constrained in the syn form. Proc. Natl. Acad. Sci. USA 1980, 77, 3398-3402. [CrossRef] [PubMed]

25. Lewis, K. Platforms for antibiotic discovery. Nat. Rev. Drug Discov. 2013, 12, 371-387. [CrossRef] 
26. Rojas, E.R.; Billings, G.; Odermatt, P.D.; Auer, G.K.; Zhu, L.; Miguel, A.; Chang, F.; Weibel, D.B.; Theriot, J.A.; Huang, K.C. The outer membrane is an essential load-bearing element in Gram-negative bacteria. Nature 2018, 559, 617-621. [CrossRef]

27. Bode, H.B.; Ring, M.W.; Schwär, G.; Altmeyer, M.O.; Kegler, C.; Jose, I.R.; Singer, M.; Müller, R. Identification of additional players in the alternative biosynthesis pathway to isovaleryl-CoA in the myxobacterium Myxococcus xanthus. ChemBioChem 2009, 10, 128-140. [CrossRef]

28. Li, Y.; Luxenburger, E.; Müller, R. An alternative isovaleryl CoA biosynthetic pathway involving a previously unknown 3-methylglutaconyl CoA decarboxylase. Angew. Chem. Int. Ed. Engl. 2012, 52, 1304-1308. [CrossRef]

29. Li, R.; Wijma, H.J.; Song, L.; Cui, Y.; Otzen, M.; Tian, Y.; Du, J.; Li, T.; Niu, D.; Chen, Y.; et al. Computational redesign of enzymes for regio- and enantioselective hydroamination. Nat. Chem. Biol. 2018, 14, 664-670. [CrossRef]

30. Severin, R.; Doye, S. The catalytic hydroamination of alkynes. Chem. Soc. Rev. 2007, 36, 1407-1420. [CrossRef]

31. Helfrich, E.J.N.; Lin, G.-M.; Voigt, C.A.; Clardy, J. Bacterial terpene biosynthesis: Challenges and opportunities for pathway engineering. Beilstein J. Org. Chem. 2019, 15, 2889-2906. [CrossRef] [PubMed]

32. Layre, E.; Lee, H.J.; Young, D.C.; Martinot, A.J.; Buter, J.; Minnaard, A.J.; Annand, J.W.; Fortune, S.M.; Snider, B.B.; Matsunaga, I.; et al. Molecular profiling of Mycobacterium tuberculosis identifies tuberculosinyl nucleoside products of the virulence-associated enzyme Rv3378c. Proc. Natl. Acad. Sci. USA 2014, 111, 2978-2983. [CrossRef]

33. Blin, K.; Shaw, S.; Steinke, K.; Villebro, R.; Ziemert, N.; Lee, S.Y.; Medema, M.H.; Weber, T. antiSMASH 5.0: Updates to the secondary metabolite genome mining pipeline. Nucleic Acids Res. 2019, 47, W81-W87. [CrossRef] [PubMed]

34. Stevens, D.C.; Young, J.; Carmichael, R.; Tan, J.; Taylor, R.E. Draft Genome Sequence of Gephyronic Acid Producer Cystobacter violaceus Strain Cb vi76. Genome Announc. 2014, 2, 2. [CrossRef] [PubMed]

35. Adaikpoh, B.I.; Dowd, S.E.; Stevens, D.C. Draft Genome Sequence of Archangium sp. Strain Cb G35. Genome Announc. 2017, 5, e01678. [CrossRef] [PubMed]

36. Giglio, S.; Jiang, J.; Saint, C.P.; Cane, D.E.; Monis, P.T. Isolation and characterization of the gene associated with geosmin production in cyanobacteria. Environ. Sci. Technol. 2008, 42, 8027-8032.

37. Jiang, J.Y.; He, X.F.; Cane, D.E. Biosynthesis of the earthy odorant geosmin by a bifunctional Streptomyces coelicolor enzyme. Nat. Chem. Biol. 2007, 3, 711-715. [CrossRef]

38. Botella, J.A.; Murillo, F.J.; Ruiz-Vazquez, R. A cluster of structural and regulatory genes for light-induced carotenogenesis in Myxococcus xanthus. Eur. J. Biochem. 1995, 233, 238-248. [CrossRef]

39. Lopez-Rubio, J.J.; Elias-Arnanz, M.; Padmanabhan, S.; Murillo, F.J. A repressor-antirepressor pair links two loci controlling light-induced carotenogenesis in Myxococcus xanthus. J. Biol. Chem. 2002, 277, 7262-7270. [CrossRef]

40. Perez-Marin, M.C.; Padmanabhan, S.; Polanco, M.C.; Murillo, F.J.; Elias-Arnanz, M. Vitamin B 12 partners the CarH repressor to downregulate a photoinducible promoter in Myxococcus xanthus. Mol. Microbiol. 2008, 67, 804-819. [CrossRef]

41. Cervantes, M.; Murillo, F.J. Role for Vitamin $B_{12}$ in Light Induction of Gene Expression in the Bacterium Myxococcus xanthus. J. Bacteriol. 2002, 184, 2215-2224. [CrossRef] [PubMed]

42. Dickschat, J.S. Bacterial terpene cyclases. Nat. Prod. Rep. 2015, 33, 87-110. [CrossRef] [PubMed]

43. Harada, F.; Gross, H.J.; Kimura, F.; Chang, S.H.; Nishimura, S.; RajBhandary, U.L. 2-Methylthio $N^{6}-\left(\Delta^{2}\right.$-isopentenyl) adenosine: A component of E. coli tyrosine transfer RNA. Biochem. Biophys. Res. Commun. 1968, 33, 299-306. [CrossRef]

44. Großkinsky, D.K.; Petrášek, J. Auxins and cytokinins-The dynamic duo of growth-regulating phytohormones heading for new shores. New Phytol. 2019, 221, 1187-1190. [CrossRef]

45. Schaller, G.E.; Bishopp, A.; Kieber, J.J. The yin-yang of hormones: Cytokinin and auxin interactions in plant development. Plant. Cell 2015, 27, 44-63. [CrossRef]

46. MacLeod, J.K.; Summons, R.E.; Parker, C.W.; Letham, D.S. Lupinic acid, a purinyl amino acid and a novel metabolite of zeatin. J. Chem. Soc. Chem. Commun. 1975, 19, 809-810. [CrossRef]

47. Abdjul, D.B.; Yamazaki, H.; Kanno, S.-I.; Takahashi, O.; Kirikoshi, R.; Ukai, K.; Namikoshi, M. Structures and Biological Evaluations of Agelasines Isolated from the Okinawan Marine Sponge Agelas nakamurai. J. Nat. Prod. 2015, 78, 1428-1433. [CrossRef] 
48. Cullen, E.; Devlin, J.P. Agelasine: A Novel Quaternary 9-Methyladenine from the Sponge Agelas dispar. Can. J. Chem. 1975, 53, 1690-1691. [CrossRef]

49. Fathi-Afshar, R.; Allen, T.M. Biologically active metabolites from Agelas mauritiana. Can. J. Chem. 1988, 66, 45-50. [CrossRef]

50. Yosief, T.; Rudi, A.; Kashman, Y. Asmarines A-F, novel cytotoxic compounds from the marine sponge Raspailia species. J. Nat. Prod. 2000, 63, 299-304. [CrossRef]

51. Gordaliza, M. Terpenyl-purines from the sea. Mar. Drugs 2009, 7, 833-849. [CrossRef]

52. Hug, J.J.; Müller, R. Host Development for Heterologous Expression and Biosynthetic Studies of Myxobacterial Natural Products: Comprehensive Natural Products III: Chemistry and Biology, Chapter 14818. Ref. Modul. Chem. Mol. Sci. Chem. Eng. 2020, in press.

53. Kearse, M.; Moir, R.; Wilson, A.; Stones-Havas, S.; Cheung, M.; Sturrock, S.; Buxton, S.; Cooper, A.; Markowitz, S.; Duran, C.; et al. Geneious Basic: An integrated and extendable desktop software platform for the organization and analysis of sequence data. Bioinformatics 2012, 28, 1647-1649. [CrossRef] [PubMed]

54. Finn, R.D.; Coggill, P.; Eberhardt, R.Y.; Eddy, S.R.; Mistry, J.; Mitchell, A.L.; Potter, S.C.; Punta, M.; Qureshi, M.; Sangrador-Vegas, A.; et al. The Pfam protein families database: Towards a more sustainable future. Nucleic Acids Res. 2016, 44, D279-D285. [CrossRef] [PubMed]

Sample Availability: Samples of the compounds sorangiadenosine and 2-hydroxysorangiadenosine are available from the authors.

(C) 2020 by the authors. Licensee MDPI, Basel, Switzerland. This article is an open access article distributed under the terms and conditions of the Creative Commons Attribution (CC BY) license (http://creativecommons.org/licenses/by/4.0/). 